\title{
Loss of OPA1 disturbs cellular calcium homeostasis and sensitizes for excitotoxicity
}

\author{
YE Kushnareva ${ }^{1,4,5}$, AA Gerencser ${ }^{1,5,6}$, B Bossy ${ }^{1,2}$, W-K Ju ${ }^{1,7}$, AD White ${ }^{3}$, J Waggoner ${ }^{3}$, MH Ellisman ${ }^{3}$, G Perkins ${ }^{3}$ and \\ E Bossy-Wetzel $\left.\right|^{*, 1,2}$
}

Optic atrophy 1 (OPA1) mutations cause dominant optic atrophy (DOA) with retinal ganglion cell (RGC) and optic nerve degeneration. The mechanism for the selective degeneration of RGCs in DOA remains elusive. To address the mechanism, we reduced OPA1 protein expression in cell lines and RGCs by RNA interference. OPA1 loss results in mitochondrial fragmentation, deficiency in oxidative phosphorylation, decreased ATP levels, decreased mitochondrial $\mathrm{Ca}^{2+}$ retention capacity, reduced mtDNA copy numbers, and sensitization to apoptotic insults. We demonstrate profound cristae depletion and loss of crista junctions in OPA1 knockdown cells, whereas the remaining crista junctions preserve their normal size. OPA1-depleted cells exhibit decreased agonist-evoked mitochondrial $\mathrm{Ca}^{2}+$ transients and corresponding reduction of $\mathrm{NAD}^{+}$to NADH, but the impairment in NADH oxidation leads to an overall more reduced mitochondrial NADH pool. Although in our model OPA1 loss in RGCs has no apparent impact on mitochondrial morphology, it decreases buffering of cytosolic $\mathrm{Ca}^{2+}$ and sensitizes RGCs to excitotoxic injury. Exposure to glutamate triggers delayed calcium deregulation (DCD), often in a reversible manner, indicating partial resistance of RGCs to this injury. However, when OPA1 is depleted, DCD becomes irreversible. Thus, our data show that whereas OPA1 is required for mitochondrial fusion, maintenance of crista morphology and oxidative phosphorylation, loss of OPA1 also results in defective $\mathrm{Ca}^{2+}$ homeostasis.

Cell Death and Differentiation (2013) 20, 353-365; doi:10.1038/cdd.2012.128; published online 9 November 2012

Mutations in optic atrophy 1 (OPA1), a dynamin-related large GTPase with mitochondrial fusion function, cause dominant optic atrophy (DOA), the most common hereditary form of optic neuropathy. ${ }^{1,2}$ Progressive degeneration of retinal ganglion cells (RGCs) and the optic nerve, the hallmarks of DOA, are associated with several functional and structural alterations of mitochondria (reviewed in Lenaers et al. ${ }^{3}$ ). Whereas the OPA1 mutation in DOA patients is present from birth in all cells, it remains unknown why only certain cell types, such as RGCs, degenerate ${ }^{4-8}$ and what are the mechanisms leading to their loss.

In addition to its role in mitochondrial fusion, OPA1 governs crista architecture. OPA1 is anchored in the mitochondrial inner membrane and faces the intermembrane space..$^{9,10}$ Electron microscopy (EM) analyses indicate that OPA1 loss causes abnormal mitochondrial ultrastructure with cristae disorganization. ${ }^{9-11}$ Interaction of OPA1 with membranes can induce a structural remodeling into tubules, ${ }^{12}$ a feature characteristic of crista junctions, ${ }^{13-15}$ supporting the proposal that OPA1 is a key component of these junctions. ${ }^{16-18}$ Because crista junctions are normally uniform, a change in their size may indicate alteration in mitochondrial functional status. Yet, disagreements have arisen concerning crista junction remodeling in apoptosis. ${ }^{17-21}$

Emerging evidence suggests that abnormal $\mathrm{Ca}^{2+}$ homeostasis contributes to the pathogenesis in DOA. ${ }^{22,23} \mathrm{Ca}^{2+}$ enters mitochondria via the $\mathrm{Ca}^{2+}$ uniporter where it stimulates $\mathrm{NADH}$ and ATP production via activation of $\mathrm{NADH}$ producing dehydrogenases including pyruvate dehydrogenase, 2-oxoglutarate dehydrogenase, and NAD-linked isocitrate dehydrogenase. ${ }^{24}$ During neurotransmission, ionotropic glutamate receptors, including the $\mathrm{N}$-methyl-D-aspartate (NMDA) receptor, open and cytoplasmic $\mathrm{Ca}^{2+}$ accumulates in neurons and regulates downstream enzymes and signaling pathways. ${ }^{25}$ However, if excessive glutamate is released into the extracellular space, for example, during stroke, epilepsy, or neuronal injury, neurons suffer excitotoxic damage. In cell culture models, a phenomenon known as delayed $\mathrm{Ca}^{2+}$

\footnotetext{
${ }^{1}$ Apoptosis \& Cell Death Program, Sanford Burnham Institute for Medical Research, La Jolla, CA 92037, USA; ${ }^{2}$ Burnett School of Biomedical Sciences, College of Medicine, University of Central Florida, Orlando, FL 32816, USA and ${ }^{3}$ National Center for Microscopy and Imaging Research, School of Medicine, University of California, San Diego, La Jolla, CA 92093, USA

*Corresponding author: E Bossy-Wetzel, Burnett School of Biomedical Sciences, College of Medicine, University of Central Florida, 4000 Central Florida Boulevard, Orlando, FL 32816, USA. Tel: 4078233384 ; Fax: 4078230956 ; E-mail: ebossywe @mail.ucf.edu

${ }^{4}$ Current address: La Jolla Institute for Allergy and Immunology, 9420 Athena Circle, La Jolla, CA 92037, USA

${ }^{5}$ These authors contributed equally to this work.

${ }^{6}$ Current address: Buck Institute for Research on Aging, 8001 Redwood Boulevard Novato, CA 94945, USA

${ }^{7}$ Current address: Hamilton Glaucoma Center and Department of Ophthalmology, University of California, San Diego, La Jolla, CA 92093, USA Keywords: calcium; mitochondria; OPA1

Abbreviations: DOA, dominant optic atrophy; $\mathrm{DCD}$, delayed $\mathrm{Ca}^{2+}$ deregulation; Drp1, dynamin-related protein 1; $\left[\mathrm{Ca}^{2+}\right]_{\mathrm{C}}$, cytoplasmic $\mathrm{Ca}^{2+}$ concentration; $\left[\mathrm{Ca}^{2+}\right]_{\mathrm{m}}$, mitochondrial $\mathrm{Ca}^{2+}$ concentration; $\Delta \psi_{\mathrm{m}}$, mitochondrial membrane potential; FCCP, carbonyl cyanide p-(trifluoromethoxy)phenylhydrazone; MPT, mitochondrial permeability transition; mtDNA, mitochondrial DNA; nDNA, nuclear DNA; OMM, outer mitochondrial membrane; RGC, retinal ganglion cell; siRNA, small interfering RNA; TPP ${ }^{+}$, tetraphenylphosphonium

Received 21.3.12; revised 23.7.12; accepted 10.9.12; Edited by JM Hardwick; published online 09.11 .12
} 
deregulation (DCD) occurs during acute glutamate exposure. $^{26,27} \mathrm{DCD}$ is thought to be a consequence of mitochondrial $\mathrm{Ca}^{2+}$ overload-mediated injury, ${ }^{28}$ and in most paradigms leads to neuronal cell death. ${ }^{29,30}$ Remarkably, RGCs are known to be resistant to excitotoxicity in contrast to hippocampal neurons. ${ }^{31}$

To investigate the mechanism of RGC degeneration in DOA, OPA1 expression in cell lines and primary RGCs was decreased by RNAi, and ultrastructure, bioenergetics, and $\mathrm{Ca}^{2+}$ homeostasis of control and RNAi cells were compared. We demonstrate that in RGCs, decreased mitochondrial $\mathrm{Ca}^{2+}$ buffering and DCD occur in the absence of significant changes in mitochondrial morphology, suggesting a functional role of OPA1 in $\mathrm{Ca}^{2+}$ signaling.

\section{Results}

OPA1 loss results in mitochondrial fission and sensitization to apoptosis. To explore the effects of OPA1 loss on cellular function we transfected cells with OPA1 small interfering RNA (siRNA). Because RGCs constitute only $1 \%$ of all cells in the retina and the yields are low after purification, we were forced to use cell lines (HeLa cells) for some experiments. Although control HeLa cells exhibited a typical fused mitochondrial network, $\sim 80 \%$ of OPA1 siRNA cells showed dramatic mitochondrial fragmentation (Figure 1a). Effective OPA1 knockdown was confirmed by immunoblotting (Supplementary Figure 1).

Previous studies have reported that cells lacking OPA1 spontaneously release cytochrome $c$ from mitochondria and undergo cell death. ${ }^{9,32}$ However, subcellular fractionation with immunoblotting (Figure 1b) and confocal microscopy of OPA1 siRNA cells (Figures $1 \mathrm{c}$ and $\mathrm{d}$ ) demonstrated that OPA1 knockdown did not result in spontaneous cytochrome $c$ release from mitochondria. Measurements of cell death by three independent methods (Figures 1e-g and Supplementary Figure 2) did not reveal greater than baseline cell death in OPA1 siRNA cells. However, in agreement with an earlier study, ${ }^{32}$ OPA1 siRNA cells died faster when challenged with staurosporine (STS), an apoptosis inducer, and exhibited a significantly higher caspase activity after STS treatment than STS-treated control cells (Figures 1e and f). Taken together, these data indicate that OPA1 loss per se does not cause cytochrome $c$ release from mitochondria or cell death; instead, it conveys an increased susceptibility to apoptosis.

OPA1 loss leads to cristae depletion. Conventional 2D EM analyses demonstrate that OPA1 loss causes abnormal mitochondrial ultrastructure. ${ }^{9-11}$ However, a detailed 3D picture and quantitative analysis of the mitochondrial ultrastructure in intact, mammalian OPA1-deficient cells are lacking. Only $3 \mathrm{D}$ reconstructions of isolated mitochondria from OPA1-null cells were published previously. ${ }^{17}$ To gain better insights into the mitochondrial ultrastructure in OPA1 knockdown cells, we performed EM tomography and a highresolution mitochondrial quantitative analysis. Through tomographic reconstructions from scrambled siRNA-transfected cells, 2-nm thick slices show elongated mitochondria and an intact outer mitochondrial membrane (OMM; Figures 2A and B; Supplementary Movie File 1). The tomographic view of mitochondria in OPA1 siRNA cells was dramatically different from controls, not surprisingly showing many more round and small mitochondria. Figures $2 \mathrm{~A}$ and Bc-f show a triplet of mitochondria from OPA1 siRNA cells whose OMMs are in close contact, suggesting recent fission before fixation. As with the control mitochondria, no signs of OMM breaks or matrix swelling were observed, consistent with our observation that cytochrome $c$ remains localized within mitochondria and spontaneous cell death does not occur. Mitochondria of OPA1 siRNA cells displayed fewer and smaller cristae (Figures 2Bc-f), with some mitochondria even devoid of cristae (Figures 2Bd and f, and Supplementary Movie File 2). A few mitochondria had cristae oriented parallel to the long axis of the organelle, unusual for HeLa cells.

Additionally, in tomographic volumes, we quantified mitochondrial numbers per cubic micron and mitochondrial volume relative to cellular volume. Although there was no difference in the total mitochondrial volume, mitochondrial number increased twofold in OPA1 siRNA-transfected cells (Figures $2 \mathrm{Ca}$ and b). These results confirm that OPA1 loss promotes mitochondrial fission rather than a decrease in mitochondrial density. We also measured cristae surface area compared with that of the OMM surface area and evaluated cristae surface area relative to cell volume (Figures $2 \mathrm{Cc}$ and d). The total cristae membrane surface area of OPA1 siRNAtransfected cells was $25 \%$ less than that of controls (Figures 2Cc and d).

OPA1 loss leads to mitochondrial structural heterogeneity, but not widening of crista junctions. Because of the report of heterogeneity in mitochondrial membrane potential $\left(\Delta \psi_{\mathrm{m}}\right)$ after OPA1 loss, ${ }^{33}$ we investigated possible accompanying structural heterogeneity. Using conventional EM, we found that $\sim 10 \%$ of mitochondria were considerably more condensed than the majority (Figures 3a-e). To clarify whether crista junction changes occurred in our OPA1 siRNA samples, we measured junctional sizes in tomographic volumes. In agreement with the previous report, ${ }^{17}$ we found that the junctional size remains essentially unaltered with loss of OPA1 (Figures $3 \mathrm{f}-\mathrm{h}$; $10.0 \pm 0.4 \mathrm{~nm}$ for control and $8.9 \pm 0.5 \mathrm{~nm}$ for OPA1 siRNA crista junctions; mean \pm S.E.M.). However, the number of junctions was significantly reduced in OPA1 siRNA mitochondria (Figure 3h; $54 \pm 4 \mathrm{CJ} / \mathrm{S}$.A. for control and $21 \pm 6 \mathrm{CJ} / \mathrm{S}$.A. for OPA1 siRNA; mean \pm S.E.M.; $P<.001)$. Loss of crista junctions is consistent with cristae depletion (Figure 2); this phenomenon was also reported in a previous study using a TOM19removal mechanism for cristae depletion. ${ }^{34}$ Collectively our findings indicate that OPA1 loss results in cristae depletion without dilation of their junctions.

OPA1 loss results in bioenergetic defects, mtDNA loss, and impaired mitochondrial $\mathrm{Ca}^{2+}$ buffering. Because mitochondrial cristae are abnormal in OPA1 siRNA cells, we investigated the impact of these abnormalities on bioenergetics. Respiratory changes induced by OPA1 knockdown were evaluated in digitonin-permeabilized and intact cells. To measure respiration in digitonin-permeabilized cells, mitochondria were supplemented with Complex I-linked substrates, glutamate and malate. The rates of ADP-induced 

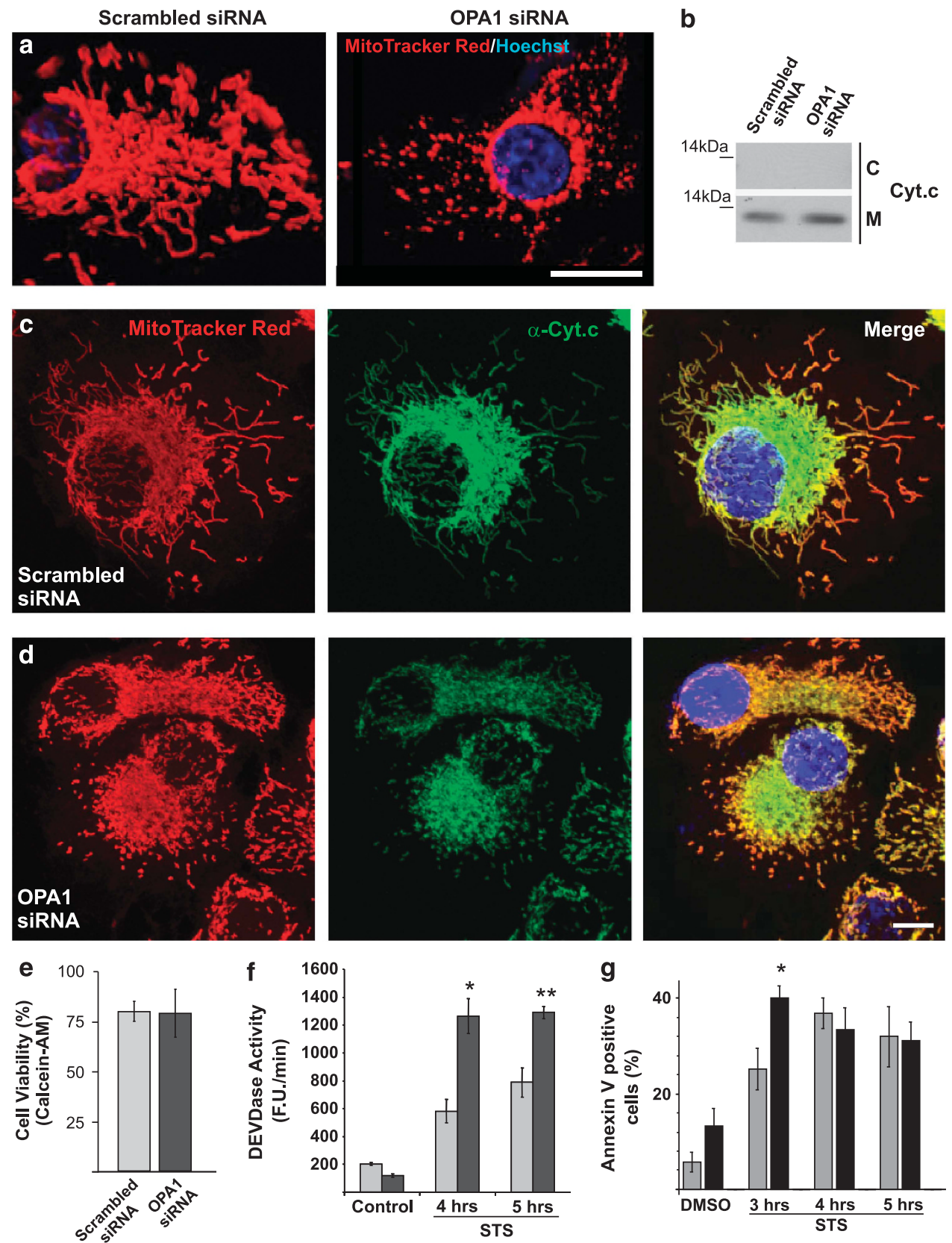

Figure 1 OPA1 loss results in mitochondrial fission without loss in cell viability. (a) Mitochondrial structure in scrambled (control) and OPA1 siRNA-transfected HeLa cells at 3 days after transfection. Mitochondria and nuclei were stained with MitoTracker Red and Hoechst 33342 (blue), respectively. Scale bar, $20 \mu \mathrm{m}$. (b) Immunoblot of cytosolic (C) and mitochondrial fraction (M) of siRNA-transfected HeLa cells probed with anti-cytochrome $c$ antibodies. (c and d) Immunocytochemistry and confocal microscopy of fixed control (c) and OPA1 siRNA-transfected (d) HeLa cells labeled with anti-cytochrome $c$ antibodies (green) and MitoTracker Red (red). Hoechst 33342 counterstaining (blue) marks nuclei. (e) Cell viability of scrambled (gray bars) and OPA1 siRNA-transfected (black bars) HeLa cells measured using Calcein-AM 3 days after transfection. (f) DEVDase activity and (g) Annexin-V labeling of scrambled (gray bars) and OPA1 siRNA-transfected (black bars) HeLa cells treated with $1 \mu \mathrm{M}$ STS for 3-5h. The rate of zDEVD-AMC cleavage is expressed in arbitrary fluorescence units per minute (FU/min). For (e-g), data are means \pm S.E.M. of three experiments $\left({ }^{*}\right.$ and ${ }^{* *}$ denote $P<0.05$ and $P<0.01$ respectively)

(state 3) and maximal (carbonyl cyanide $p$-(trifluoromethoxy) phenylhydrazone (FCCP)-induced or state $3 u$ ) respiration were reduced by $\sim 20 \%$ in OPA 1 siRNA cells compared with controls (Figure 4A and Table 1). Comparable inhibition of respiration was observed in intact OPA1 siRNA cells (Table 1). Note that the oligomycin-inhibited (state 40) respiration, an indicator of proton leak through the inner mitochondrial membrane, remained unaltered in digitoninpermeabilized and intact OPA1 siRNA cells (Figure 4A). Thus, OPA1 loss does not induce proton leak and mitochondrial uncoupling, but rather causes partial respiratory inhibition. 

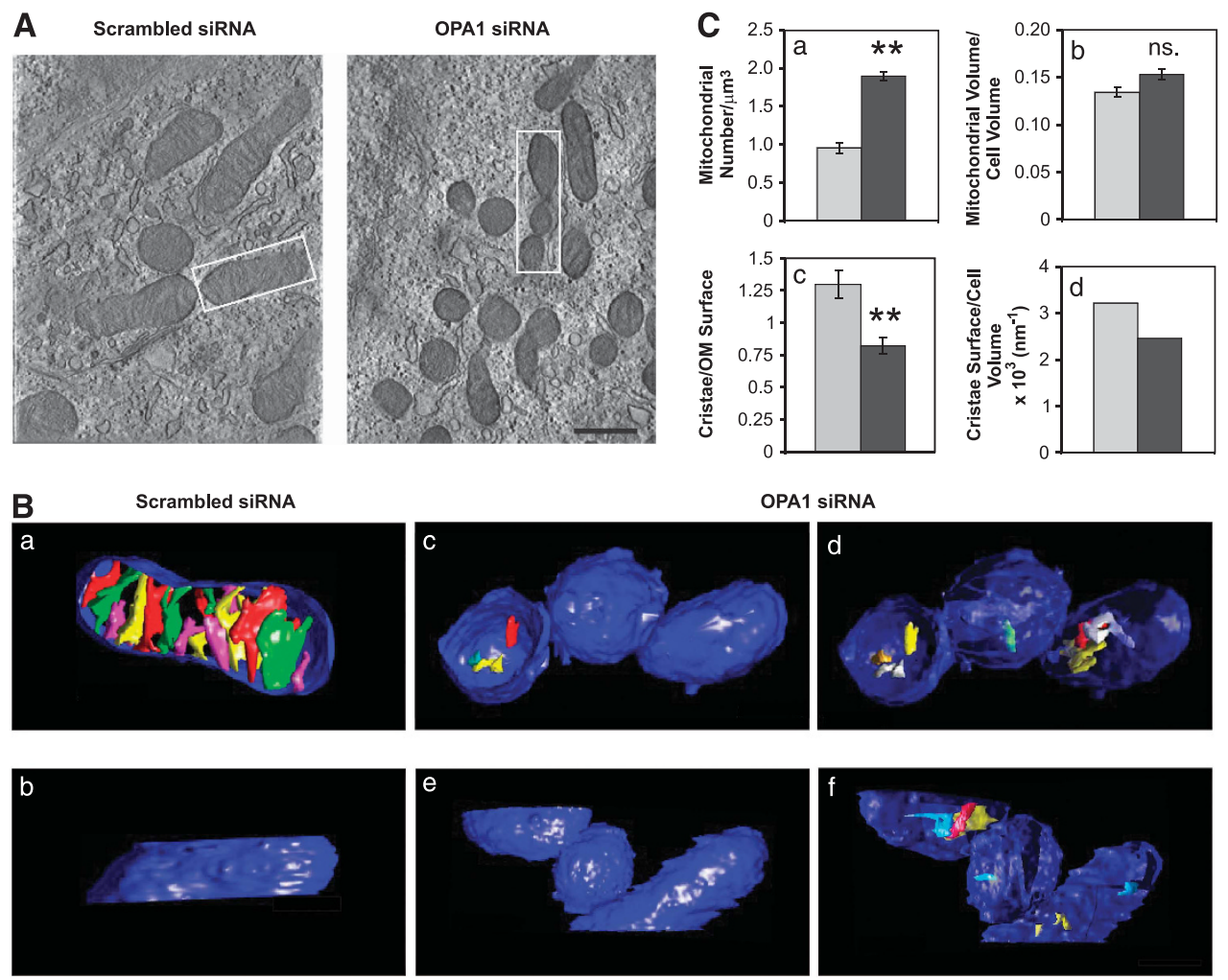

Figure 2 OPA1 loss leads to mitochondrial fission and cristae abnormalities. (A) Two 2-nm thick slices through EM tomographic volumes of mitochondria in fixed scrambled (control) and OPA1 siRNA-transfected HeLa cells in situ. Scale bar, $500 \mathrm{~nm}$. White rectangle marks mitochondria chosen for volume segmentation and surface rendering. (B) Surface-rendered volumes of a segmented control mitochondrion and three segmented OPA1 siRNA mitochondria found in close proximity. The OMM is in blue and cristae are in various colors. (a) Top view of control mitochondrion after segmentation of the outer and cristae membranes into separate objects. (b) Side view of the OMM showing no ruptures. (c and d) Top view of a mitochondrial triplet in OPA1 siRNA-transfected HeLa cells. (e and f) View of same triplet from a side orientation. ( $d$ and f) Mitochondria are shown with translucent representation of the OMM to visualize the cristae. Scale bar, $200 \mathrm{~nm}$. (C) Structural analysis of mitochondria by EM tomography. For mitochondrial number and volume, $n$ (number of measured mitochondria) $=41$ (scrambled siRNA, light gray bars) and 60 (OPA1 siRNA, black bars) $\left.{ }^{* *} P<0.01\right)$. For cristae surface area (per outer membrane surface area) measurements, $n=12$ (scrambled siRNA) and 23 (OPA1 siRNA) were used; the same samples were used to determine total cristae surface in the reconstituted volume per cell volume. Data are means \pm S.E.M. In (d), all of the cristae in the reconstructed volume were summed

The maximal rate of respiration may be limited by the transport of substrates and/or activity of the tricarboxylic acid cycle, in addition to the activity of the electron transport chain. To directly test Complex I activity coupled with the activity of downstream complexes, we measured rotenone-sensitive $\mathrm{NADH}$-dependent respiration in alamethicin-permeabilized mitochondria. Figure 4B illustrates that the activity of electron transport chain (Complexes I-III-IV) was reduced by $39 \pm 4 \%$ $(n=4)$ in OPA1 siRNA cells. Consistent with the reduced respiratory capacity, OPA1 siRNA cells displayed lower ATP levels (Figure 4C).

Next, we determined the mitochondrial DNA copy number by quantitative PCR. The mitochondrial DNA (mtDNA) to nuclear DNA (nDNA) ratio was significantly decreased in OPA1 siRNA cells (Figure 4D). Thus, mitochondrial crista depletion and the mtDNA copy number decrease may be the causes of partial respiratory inhibition resulting from OPA1 loss.

To dissect further the downstream mechanism of mitochondrial dysfunction in OPA1 siRNA cells, we assessed mitochondrial $\mathrm{Ca}^{2+}$ retention capacity using digitonin-permeabilized cells. Extramitochondrial $\mathrm{Ca}^{2+}$ concentration
(Figure 4Ea) was measured simultaneously with measurements of $\Delta \psi_{\mathrm{m}}$ (Figure 4Eb) and mitochondrial swelling (Figure 4Ec) in a multiparameter chamber. Control and OPA1 knockdown cells were repetitively challenged with small $\mathrm{Ca}^{2+}$ pulses. At baseline, OPA1 siRNA cells exhibited a $\Delta \psi_{\mathrm{m}}$ similar to scrambled siRNA cells (Figure 4Eb). Accordingly, the initial rates of $\mathrm{Ca}^{2+}$ uptake were similar. Repeated $\mathrm{Ca}^{2+}$ additions caused a gradual decline in $\Delta \psi_{\mathrm{m}}$ (Figure 4Eb) followed by abrupt depolarization, release of accumulated $\mathrm{Ca}^{2+}$ (Figure 4Ea), and mitochondrial swelling (Figure 4Ec), all indications of the mitochondrial permeability transition (MPT). Although $\mathrm{Ca}^{2+}$-induced MPT occurred in both control and OPA1 siRNA cells, the threshold concentration of $\mathrm{Ca}^{2+}$ needed to trigger mitochondrial $\mathrm{Ca}^{2+}$ release was significantly lower in OPA1 siRNA cells (Figure 4E). An 25\% decrease in $\mathrm{Ca}^{2+}$ retention capacity was observed (Figure 4F).

OPA1 loss alters histamine-induced $\mathrm{Ca}^{2}+$ transients in intact HeLa cells. Because mitochondrial $\mathrm{Ca}^{2+}$ retention capacity was reduced in digitonin-permeabilized OPA1 siRNA cells, we tested $\mathrm{Ca}^{2+}$ homeostasis in situ using live 

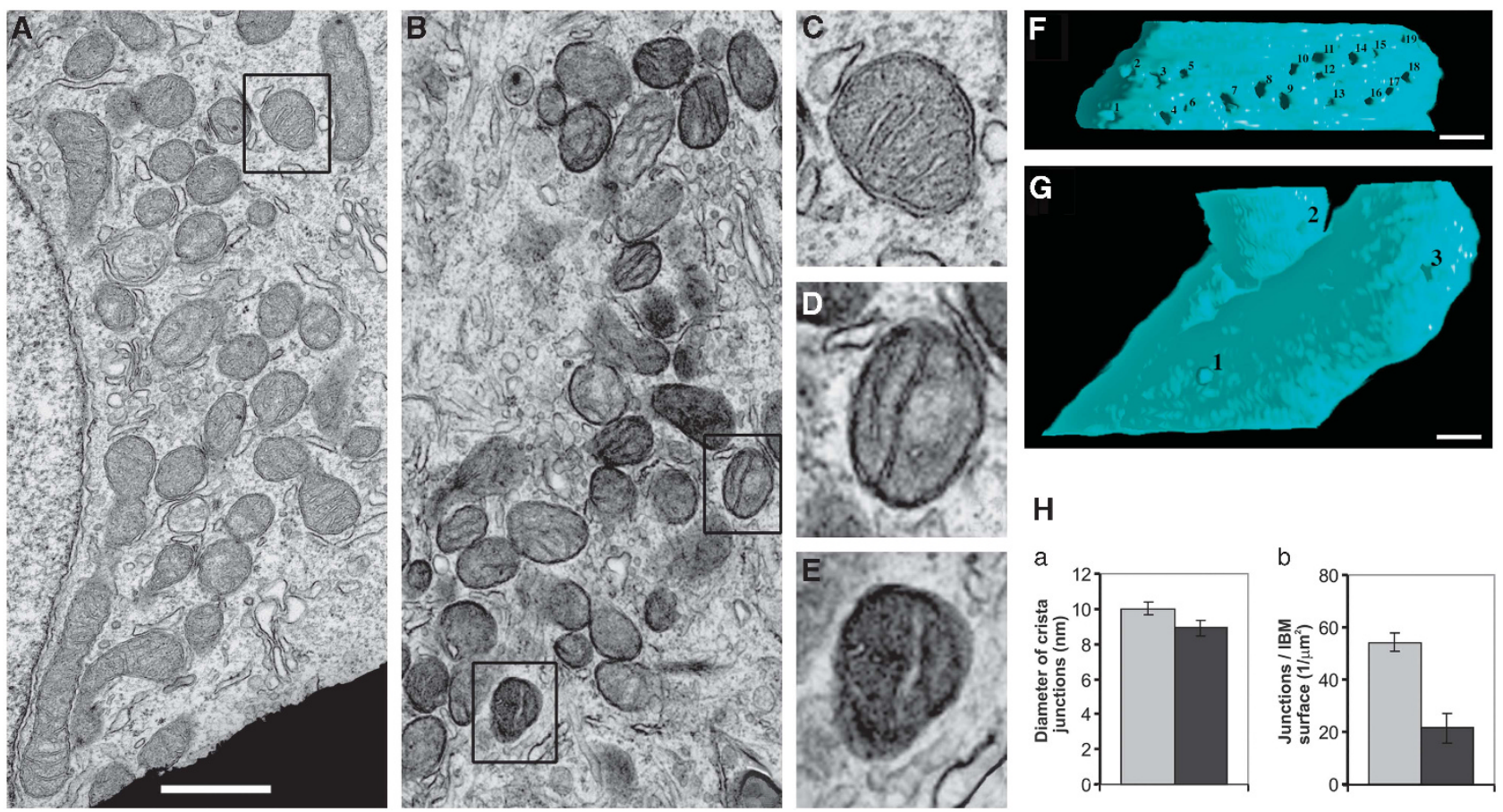

Figure 3 OPA1 loss leads to mitochondrial structural heterogeneity and depletion of crista junctions, but not their dilation. (A) Electron micrograph showing a field inside a control HeLa cell densely populated with mitochondria having uniform structural features. Scale bar, $500 \mathrm{~nm}$. (B) Electron micrograph showing a field inside an OPA1 siRNA cell densely populated with mitochondria displaying structural heterogeneity in the form of greater matrix condensation in a number of organelles. Same scale as (a). (C) Typical mitochondrial structure in control cells showing well-formed and abundant cristae with light matrix, enlarged from the boxed region in (A). (D) An example of the structure of the majority of mitochondria in OPA1 siRNA cells showing well-formed yet less abundant cristae than in the control, but still having a light matrix, enlarged from the upper boxed region in (C). (E) An example of the structure of the minority of mitochondria in OPA1 siRNA cells again showing less abundant cristae, but having a dark (condensed) matrix, enlarged from the lower boxed region in (B). (F) Inner mitochondrial membrane of the segmented tomographic volume from the scrambled siRNA sample and (G) from the OPA1 siRNA sample. By not displaying the outer membrane, the crista junction openings are easily seen (numbered). In all, 19 crista junctions are in view for the control volume, yet only 3 such junctions are in view for the OPA1 siRNA volume. Scale bar, $50 \mathrm{~nm}$. (H) Crista junction measurements from the volumes. The junctional opening in OPA1 siRNA mitochondria remains roughly circular with a diameter essentially the same as the control junction (a). In all, 52 crista junctions were measured for control (gray bar) and 47 crista junctions for OPA1 siRNA (black bar) mitochondria. For 11 control mitochondria (gray bar) and 26 OPA1 siRNA mitochondria (black bar), the number of crista junctions per mitochondrion was measured and then normalized to each inner boundary membrane surface area (measured from the segmented volume) to determine the density of junctions (b). The crista junction density for the OPA1 siRNA mitochondria was less than half for the control mitochondria; $P<0.001$

cell and fluorescence time-lapse microscopy. Mitochondrial and cytosolic $\mathrm{Ca}^{2+}$ concentrations $\left(\left[\mathrm{Ca}^{2+}\right]_{\mathrm{m}}\right.$ and $\left[\mathrm{Ca}^{2+}\right]_{\mathrm{c}}$, respectively) were assessed with the $\mathrm{Ca}^{2+}$-sensitive fluorescent probe Rhod-2-AM using high-pass filtering of recorded fluorescence images. ${ }^{35}$

To elicit intracellular $\mathrm{Ca}^{2+}$ loads, cells were repeatedly challenged with short pulses of histamine, which induces inositol 1,4,5-triphosphate ( $\left.\operatorname{InsP}_{3}\right)$-mediated release of $\mathrm{Ca}^{2+}$ from the endoplasmic reticulum (ER). We first assessed $\left[\mathrm{Ca}^{2+}\right]_{\mathrm{m}}$ in control and OPA1 siRNA cells. The amplitude of the $\left[\mathrm{Ca}^{2+}\right]_{m}$ transient caused by the first histamine pulse was significantly decreased in OPA1 siRNA cells compared with controls (Figures $5 \mathrm{Aa}$ and b). However, $\left[\mathrm{Ca}^{2+}\right]_{\mathrm{m}}$ transients in response to all subsequent histamine stimuli were not significantly different in either amplitude or decay kinetics between both cells (Figures $5 \mathrm{Ab}$ and $\mathrm{c}$ ). In contrast, histamine-triggered $\left[\mathrm{Ca}^{2+}\right]_{c}$ transients were significantly larger in OPA1 siRNA cells than in controls. This difference was also more pronounced for the first histamine pulse (Figures $5 \mathrm{Ba}$ and $\mathrm{b}$ ). Additionally, the decay rate of $\left[\mathrm{Ca}^{2+}\right]_{\mathrm{c}}$ transients was significantly higher in OPA1 siRNA cells than in controls (Figure $5 \mathrm{Bb}$ and $\mathrm{c}$ ). In summary, these data support that OPA1 siRNA cells exhibit an impaired mitochondrial $\mathrm{Ca}^{2+}$ uptake and reduced buffering of cytosolic $\mathrm{Ca}^{2+}$ (Figure 4).

OPA1 loss leads to augmented reduction of the NAD(H) pool. $\mathrm{Ca}^{2+}$ activates NADH-producing dehydrogenases in the mitochondrial matrix, thereby increasing the NADH/ $\mathrm{NAD}^{+}$ratio and rate of ATP synthesis. ${ }^{24} \mathrm{NADH}$ and NADPH exhibit indistinguishable autofluorescence, but under our experimental conditions, changes in $\mathrm{NAD}(\mathrm{P}) \mathrm{H}$ autofluorescence intensity are expected to reflect changes in the reduction state of the mitochondrial $N A D(H)$ pool. This is because the pool size of $\operatorname{NADP}(H)$ is a fraction of the NAD $(H)$ pool size, and is almost completely reduced under physiological conditions. To evaluate the $\mathrm{Ca}^{2+}$-dependent bioenergetic status in situ, we measured the $N A D(P) H$ autofluorescence in OPA1 siRNA cells. $\left[\mathrm{Ca}^{2+}\right]$ transients were evoked by exposure to repetitive histamine pulses. Each histamine application triggered a transient increase in fluorescence reflecting increased reduction of $\mathrm{NAD}^{+}$to $\mathrm{NADH}$ (Figure 6Aa). Consistent with the $\left[\mathrm{Ca}^{2+}\right]_{\mathrm{m}}$ transients 
A

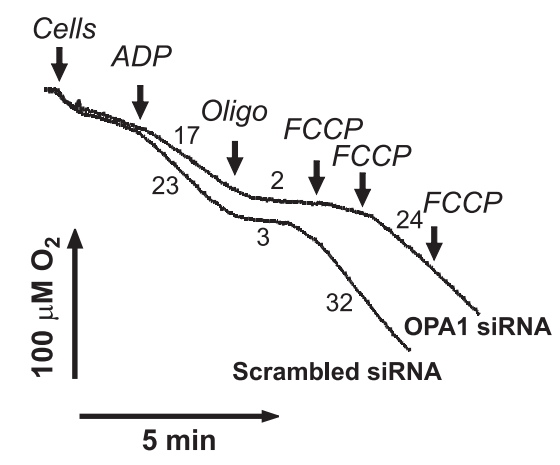

E Scrambled siRNA

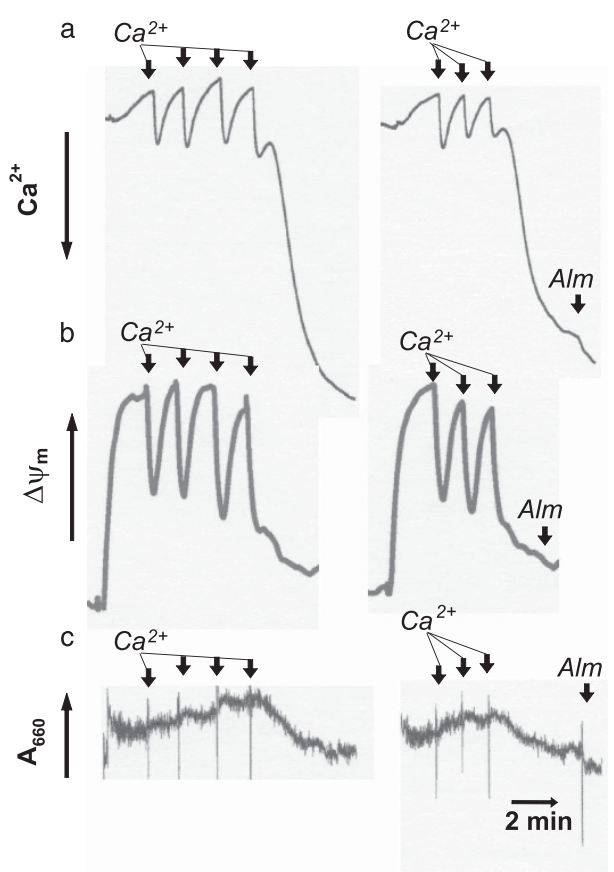

B
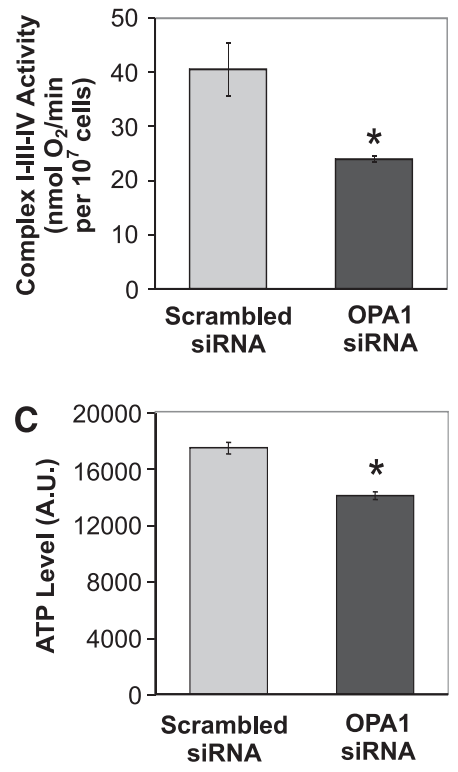

D
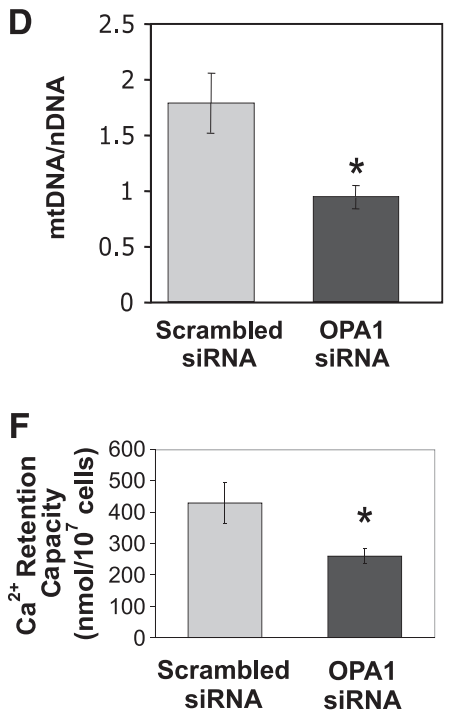

Figure 4 OPA1 loss leads to mitochondrial respiration inhibition, ATP drop, and decrease in mtDNA copy number, and compromises mitochondrial $\mathrm{Ca}^{2+}$ retention capacity. (A) Mitochondrial respiration was measured in digitonin-permeabilized HeLa cells. Arrows indicate additions of cells $\left(8 \times 10^{6}\right), 200 \mu \mathrm{M} \mathrm{ADP}, 1.25 \mu \mathrm{g} / \mathrm{ml}$ oligomycin, and $100 \mathrm{nM} \mathrm{FCCP.} \mathrm{Oxygen} \mathrm{consumption} \mathrm{rates} \mathrm{are} \mathrm{expressed} \mathrm{in} \mathrm{nmol} \mathrm{of} \mathrm{O}_{2}$ per min per $10^{7}$ cells. (B) Complex I-III-IV enzyme activity is expressed as mean \pm S.E.M. of four independent experiments. *Significance at $P<0.01$ by Student's $t$-test. (C) ATP levels in scrambled and OPA1 siRNA-transfected HeLa cells expressed as arbitrary luminescence units (AU). Data were collected from replicate wells $(n=6)$ and plotted as means \pm S.E.M.; *Significance at $P<0.01$ by Student's $t$-test. Data shown are representative of eight experiments. (D) MtDNA to nDNA ratio of scrambled and OPA1 siRNA-transfected cells $(n=6)$ measured by Q-PCR and plotted as mean \pm S.E.M. *Significance at $P<0.01$ by Mann-Whitney test. (E) Mitochondrial $\mathrm{Ca}^{2+}$ retention capacity was determined in digitonin-permeabilized HeLa cells. Sequential $\mathrm{Ca}^{2+}$ additions cause release of accumulated $\mathrm{Ca}^{2+}$ from mitochondria (a), $\Delta \psi_{\mathrm{m}}$ decline (b), and mitochondrial swelling (as indicated by a decrease in $\mathrm{A}_{660}$ ) (c), all attributable to MPT induction. Alamethicin (Alm) was added to induce maximal swelling. Arrows indicate timing of additions of $50 \mu \mathrm{M} \mathrm{Ca}{ }^{2}$ and $20 \mu \mathrm{g} / \mathrm{ml}$ Alm. Data are representative of four experiments. (F) Mitochondrial $\mathrm{Ca}^{2+}$ retention capacity in scrambled and OPA1 siRNA cells. Data are means \pm S.E.M. of four independent experiments. ${ }^{*}$ Significance at $P<0.05$ by Student's $t$-test

shown in Figure 5, the relative peak amplitude triggered by the first application of histamine was diminished in OPA1 siRNA compared with control cells (Figure 6B). The decay time of $\mathrm{NAD}(\mathrm{P}) \mathrm{H}$ signals was shorter (Figure $6 \mathrm{C}$ ) in OPA1 siRNA cells than in controls, which is consistent with the lower $\mathrm{Ca}^{2+}$ uptake capacity (Figures $5 \mathrm{Aa}$ and b). To measure the $\mathrm{NADH} / \mathrm{NAD}^{+}$ratio after a series of histamine stimuli, autofluorescence was calibrated by first oxidizing mitochondrial $\mathrm{NADH}$ to $\mathrm{NAD}^{+}$by uncoupling respiration using FCCP. Following FCCP treatment, Complex I was inhibited by rotenone and the substrate $\beta$-hydroxy-butyrate was added allowing maximal reduction of $\mathrm{NAD}^{+}$to $\mathrm{NADH}$ (Figure 6A). In control cells, the reduction level of NAD(H) pool returned to baseline following the histamine series 
Table 1 Effects of OPA1 knockdown on mitochondrial respiration in different metabolic states

\begin{tabular}{|c|c|c|c|c|}
\hline & \multirow[b]{2}{*}{ Metabolic state } & \multicolumn{2}{|c|}{ Respiration rates, $\mathrm{O}_{2} \mathrm{nmol} / \mathrm{min}$ per $10^{7}$ cells } & \multirow[b]{2}{*}{$\begin{array}{l}\text { Inhibition of respiration by } \\
\text { OPA1 knockdown: \% inhibition }\end{array}$} \\
\hline & & $\begin{array}{c}\text { Control } \\
\text { (scrambled siRNA) }\end{array}$ & $\begin{array}{l}\text { OPA1 knockdown } \\
\text { (OPA1 siRNA) }\end{array}$ & \\
\hline Permeabilized cells $(n=6)$ & $\begin{array}{l}V_{3}{ }^{*} \\
V_{4} \\
V_{3 u^{*}}\end{array}$ & $\begin{array}{r}16.7 \pm 1.6 \\
3.3 \pm 0.2 \\
20.2 \pm 2.5\end{array}$ & $\begin{array}{r}13.4 \pm 1.0 \\
3.1 \pm 0.3 \\
17.3 \pm 1.9\end{array}$ & $\begin{array}{r}19.1 \pm 2.2 \\
6.4 \pm 7.9 \\
14.0 \pm 4.5\end{array}$ \\
\hline Intact cells $(n=8)$ & $\begin{array}{c}\mathrm{V}_{\text {basal }}{ }^{\star} \\
\mathrm{V}_{3 u^{*}}{ }^{\star}\end{array}$ & $\begin{array}{r}17.2 \pm 1.9 \\
8.8 \pm 6.3 \\
25.0 \pm 2.0\end{array}$ & $\begin{array}{r}13.0 \pm 1.2 \\
6.3 \pm 0.5 \\
18.3 \pm 1.6\end{array}$ & $\begin{array}{l}21.0 \pm 5 \\
15.7 \pm 12.1 \\
26.0 \pm 4\end{array}$ \\
\hline
\end{tabular}

Data are means \pm S.E.M.; $n$, number of experiments. To determine the percent inhibition, respiration rates for each experiment were pairwise normalized to corresponding rates in the control (defined as $100 \%$ )

*Significant at $P<0.05$ by paired Student's $t$-test

(Figure 6D). In contrast, OPA1 siRNA cells exhibited a higher $\mathrm{NADH} / \mathrm{NAD}^{+}$ratio (Figure $6 \mathrm{D}$ ). An accumulation of $\mathrm{NADH}$ after a histamine-evoked $\left[\mathrm{Ca}^{2+}\right]$ rise in OPA1 siRNA cells is consistent with a defective respiratory capacity, and this outweighs the diminished NADH production caused by decreased $\mathrm{Ca}^{2+}$ uptake.

OPA1 loss in RGCs has no impact on mitochondrial morphology, but triggers glutamate-induced DCD. To test the effects of OPA1 loss on $\mathrm{Ca}^{2+}$ homeostasis in a pathophysiological setting relevant to optic neuropathies, we purified RGCs by immunopanning. ${ }^{36}$ Because RGC transfection efficiency was low, we labeled the siRNA with fluorescein (FAM) and determined the $\left[\mathrm{Ca}^{2+}\right]_{c}$ only of FAM-positive RGCs. Scrambled and OPA1 siRNA-transfected cells were stained similarly with MitoTracker Red (Figure 7 and Supplementary Figure 3) that indicated no substantial mitochondrial depolarization (as was also observed in HeLa cells; Figures $1 \mathrm{~A}$ and $4 \mathrm{E})$. In contrast to HeLa cells, scrambled and OPA1 siRNA-transfected RGCs exhibited similar, short mitochondria (Figure 7a). Neither mitochondrial length nor the longitudinal fraction of RGC processes occupied by mitochondria was significantly affected by OPA1 knockdown (Figure 7a and Supplementary Figure 3). To test whether OPA1 loss in RGCs has an impact on $\mathrm{Ca}^{2+}$ homeostasis, we measured $\left[\mathrm{Ca}^{2+}\right]_{c}$ using a low-affinity $\left(K_{\mathrm{d}}=2.9 \mu \mathrm{M}\right)$ fluorescent $\mathrm{Ca}^{2+}$ dye, Fura-FF, which is a sensitive indicator of both physiological and pathological $\mathrm{Ca}^{2+}$ levels.

We employed two experimental paradigms to evoke $\mathrm{Ca}^{2+}$ overload in RGCs. In the first paradigm, repetitive pulses of high extracellular $\left[\mathrm{K}^{+}\right]$were used to induce plasma membrane depolarization and $\mathrm{Ca}^{2+}$ entry into the cytoplasm via voltage-dependent $\mathrm{Ca}^{2+}$ channels. The resulting cytoplasmic $\left[\mathrm{Ca}^{2+}\right]$ transients were increased in OPA1 siRNA cells compared with scrambled siRNA controls, especially after repetitive stimulations; this difference was observed in a subset of OPA1 siRNA-transfected RGCs (5 out of 22; Figure 7b) but never in control RGCs. Because $\mathrm{Ca}^{2+}$ extrusion rates depend on the actual $\left[\mathrm{Ca}^{2+}\right]_{\mathrm{C}}$, we evaluated recovery of $\left[\mathrm{Ca}^{2+}\right]_{\mathrm{c}}$ after washout of the high $\left[\mathrm{K}^{+}\right]$medium by measuring the decay rate uniformly when $\left[\mathrm{Ca}^{2+}\right]_{c}$ was $\sim 0.75 \mu \mathrm{M}$. The recovery after the peak was initially faster in OPA1 siRNA-transfected RGCs compared with controls (see higher extrusion rates in Figure $7 \mathrm{~b})$. The faster drop of $\left[\mathrm{Ca}^{2+}\right]_{\mathrm{c}}$ after washout of high $\left[\mathrm{K}^{+}\right]$medium is consistent with decreased buffering of intracellular $\mathrm{Ca}^{2+}$. This could be because of decreased mitochondrial $\mathrm{Ca}^{2+}$ uptake, or decreased release of mitochondrially accumulated $\mathrm{Ca}^{2+}$ during the recovery phase of the $\left[\mathrm{Ca}^{2+}\right]_{c}$ transient. The $\mathrm{Ca}^{2+}$ extrusion slowed significantly after the third challenge in OPA1 RNAi, but not in control RGCs, indicating a progressive, stimulation-evoked deterioration of $\mathrm{Ca}^{2+}$ homeostasis.

In the second paradigm, sustained levels of glutamate were applied to induce $\mathrm{Ca}^{2+}$ entry via glutamate receptors. This challenge caused an immediate small transient increase of $\left[\mathrm{Ca}^{2+}\right]_{\mathrm{c}}$, followed by a plateau and a secondary highmagnitude $\left[\mathrm{Ca}^{2+}\right]_{c}$ rise known as DCD (Figure 7c). A significant proportion of control RGCs (6 out of 18) exhibited spontaneous reversibility of DCD, whereas in all OPA1 siRNA-transfected cells the secondary rise of $\left[\mathrm{Ca}^{2+}\right]_{\mathrm{c}}$ was sustained and irreversible for the duration of the recording (Figure 7c). Thus, OPA1 knockdown in RGCs conferred increased sensitivity to glutamate-mediated excitotoxicity, which may provide a mechanistic explanation for their degeneration in DOA.

\section{Discussion}

OPA1 is a key mediator of mitochondrial fusion, but it is currently unclear whether defects in OPA1-mediated fusion function are solely responsible for $R G C$ degeneration in DOA. ${ }^{8}$ Whereas HeLa cells exhibit a fused mitochondrial network that fragments into multiple round mitochondria after OPA1 loss, we report here that RGCs have much shorter mitochondria at baseline and undergo no significant change in size and shape upon OPA1 depletion. Previous studies reported mitochondrial fragmentation in OPA1 knockdown RGCs. ${ }^{23,37}$ However, morphological changes become apparent at longer post-transfection times (1 to 2 weeks), but not at 3 days after transfection. ${ }^{37}$ Morphological changes coincided with induction of apoptosis and membrane depolarization. ${ }^{23}$ All our experiments were performed no later than 3 days after transfection. Notably, despite a lack of mitochondrial shape transformation (Figure 7 and Supplementary Figure 3), we observed a significant change in $\mathrm{Ca}^{2+}$ handling. Thus, we propose that in RGCs, impaired $\mathrm{Ca}^{2+}$ homeostasis and DCD represent an early consequence of OPA1 loss, whereas other 

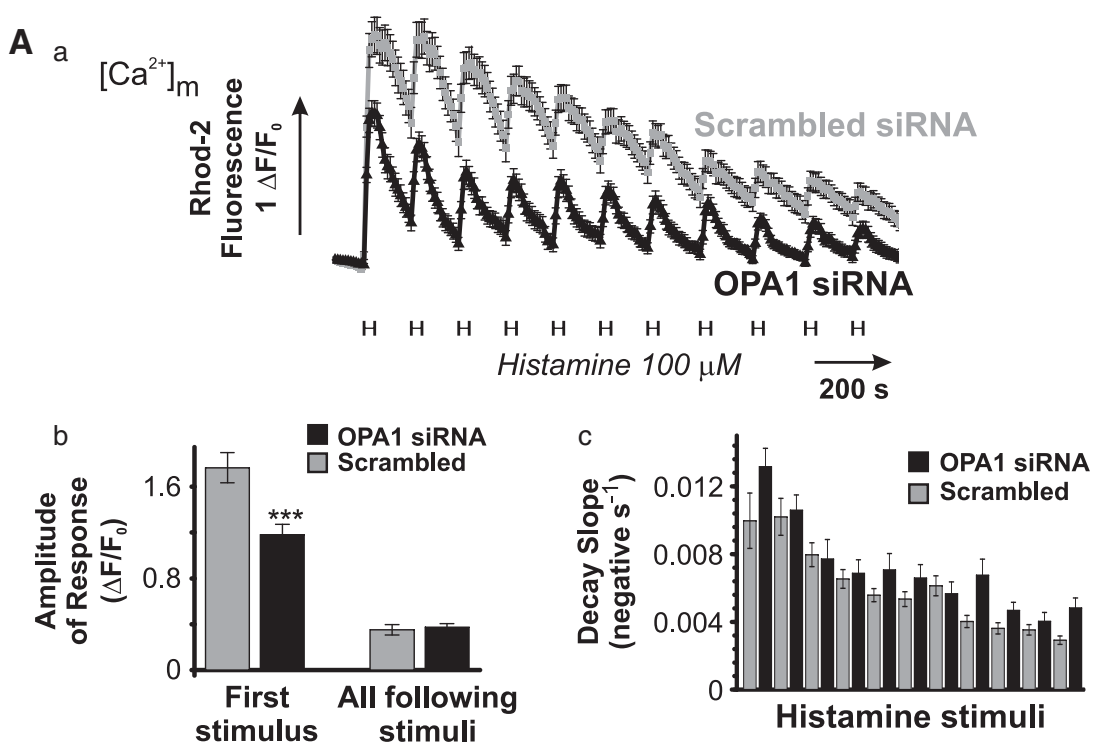

B a $\left[\mathrm{Ca}^{2+}\right]_{\mathrm{C}}$

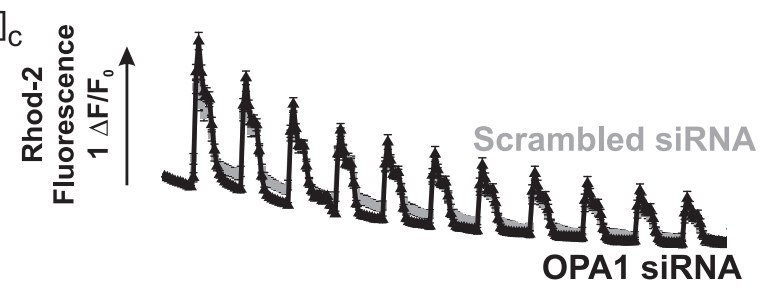

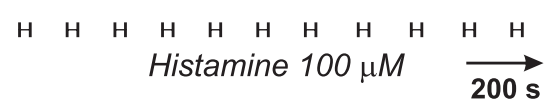
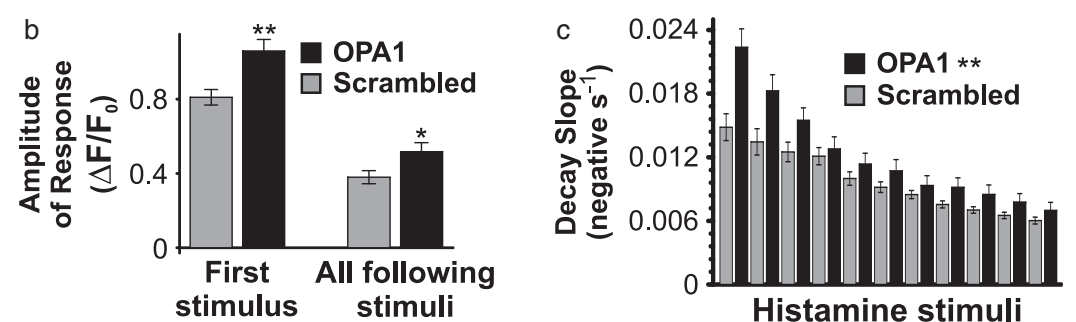

Figure 5 Effect of OPA1 knockdown on histamine-induced mitochondrial and cytoplasmic $\left[\mathrm{Ca}^{2+}\right]$ transients. Measurements of mitochondrial $(\mathbf{A})$ and cytoplasmic $(\mathbf{B})$ $\left[\mathrm{Ca}^{2+}\right.$. siRNA-transfected HeLa cells were loaded with $2 \mu \mathrm{M}$ Rhod-2-AM and stimulated by repeated application and washout of $100 \mu \mathrm{M}$ histamine for $20 \mathrm{~s}$, as indicated. (a) Scrambled siRNA and OPA1 siRNA-cells are represented by gray and black traces, respectively. Data points are means \pm S.E.M. of individual cells; $n=37$ and $n=41$ in 6 and 5 separate experiments for scrambled and OPA1 siRNA, respectively. (b) Relative peak amplitude of the initial $\left[\mathrm{Ca}^{2+}\right]$ transient and the average of the relative peak amplitudes of all following transients. Bars show means \pm S.E.M of cells corresponding to (a). ${ }^{* * *}$, ${ }^{* *}$, and ${ }^{*}$ significance at $P<0.001, P<0.01$, and $P<0.05$, respectively, by Student's t-test. (c) Decay slopes of sequential $\left[\mathrm{Ca}^{2+}\right]$ transients (from left to right) approximated by linear regression of the trace immediately following the peak; in a $60-\mathrm{s}$ span for mitochondria (Ac) and in a 20-s span for cytosol (Bc). Bars show means \pm S.E.M. of cells corresponding to (a). ${ }^{*}$ Significance at $P<0.01$ by two-way ANOVA comparing OPA1 (black) with scrambled (gray) siRNA categories

defects associated with fusion deficiency are possibly secondary or delayed effects.

Bioenergetic defects. The trigger for RGC loss in DOA likely has several components, not least of which is a bioenergetic crisis, and may also involve altered mitochondrial network dynamics, defective mtDNA maintenance, and disrupted axonal transport. ${ }^{8}$ We found partial inhibition of respiration and decreased enzyme activity of electron transport chain complexes, but $\Delta \psi_{\mathrm{m}}$ remained sufficiently high to support energy-dependent $\mathrm{Ca}^{2+}$ uptake (Figure 4). In contrast, loss of mitochondrial fusion resulted in almost complete inhibition of respiration in mouse embryonic fibroblasts, ${ }^{33}$ highlighting the variability of findings using different cellular models.

Because respiration inhibition quantitatively correlates with crista surface area reduction (25\%; Figure 2), the partial loss of cristae observed here may be responsible for the bioenergetic deficiency seen in OPA1 siRNA cells and the moderate ATP decrease observed. Respiratory inhibition is consistent with observed excessive reduction of pyridine nucleotides (Figure 6), and this effect outweighs the 
A a
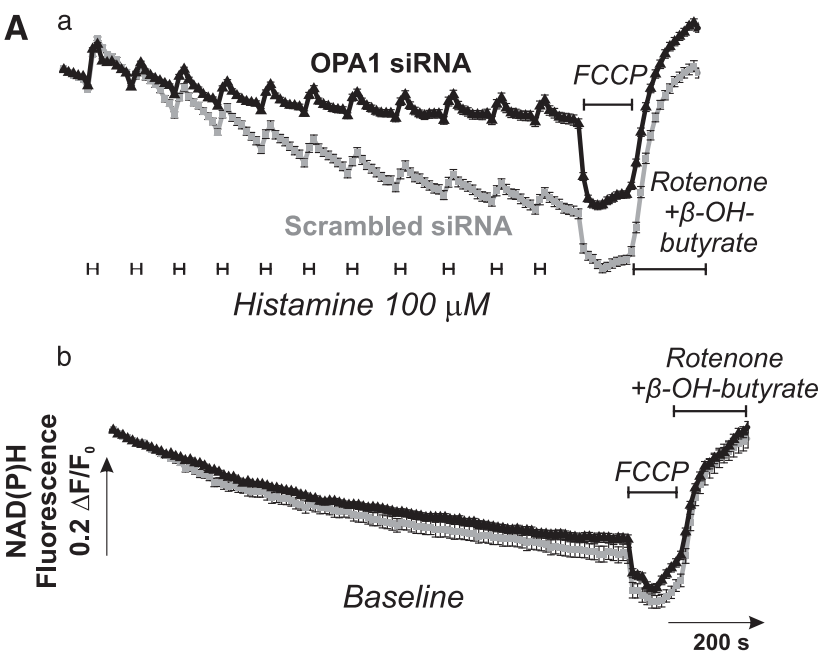

B

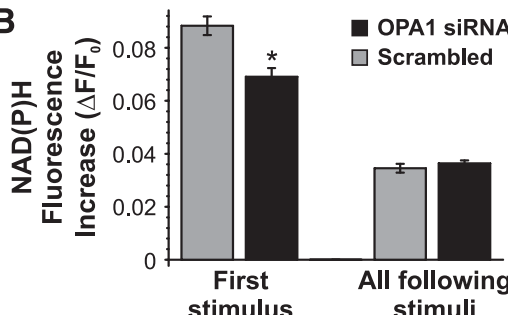

D

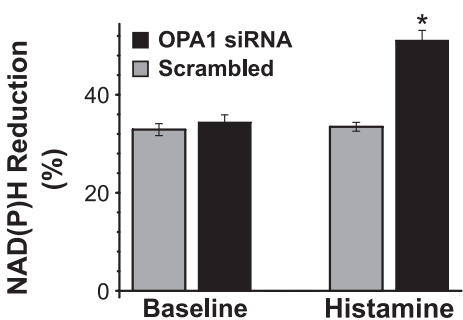

Figure 6 OPA1 knockdown leads to more reduced mitochondrial pyridine nucleotide pool. (A) Histamine-stimulated autofluorescence (a) and baseline NAD(P)H autofluorescence (b). Scrambled siRNA and OPA1 siRNA-treated HeLa cells are represented by gray and black traces, respectively. Data points show means \pm S.E.M. of $n=44$ and $n=49$ cells in 3 separate experiments for scrambled and OPA1 siRNA, respectively, for baseline traces; $n=122$ and $n=103$ in separate experiments for scrambled and OPA1 siRNA, respectively, for histaminetreated cells. To determine the redox status of the mitochondrial NADH/NAD ${ }^{+}$pool at the end of each experiment, mitochondrial NADH was fully oxidized to NAD ${ }^{+}$ with $1 \mu \mathrm{M}$ FCCP ( $0 \%$ reduction) followed by inhibition of complex I with rotenone $(1 \mu \mathrm{M})$ plus substrate ( $\beta$-hydroxy-butyrate; $10 \mathrm{mM}$ ) to fully reduce $\mathrm{NAD}^{+}$to $\mathrm{NADH}$ (100\% reduction). (B) Bar graph shows the peak amplitude of the initial transient and the average of the relative peak amplitudes of all subsequent transients of $\mathrm{NAD}(\mathrm{P}) \mathrm{H}$ autofluorescence upon histamine stimuli. (C) Bar graph shows average decay half-time of sequential autofluorescence transients approximated by exponential regression of the $60 \mathrm{~s}$ span of the trace immediately following the peak. (D) Analysis of mitochondrial redox status after histamine stimuli in experiments shown in (A). Bar graph shows the resulting NADH redox status expressed as percentage. Gray bars, scrambled siRNA; black bars, OPA1 siRNA. (B-D) Data are means \pm S.E.M. of all cells corresponding to (A). *Significant difference between OPA1 and scrambled siRNA transfection at $P<0.05$ by Student's t-test

decreased activation of dehydrogenases by the reduced $\mathrm{Ca}^{2+}$ transients. Postexercise phosphocreatine resynthesis, a measure of mitochondrial ATP generation, is delayed in patients with OPA1 mutations, ${ }^{38}$ lending further support for OPA1 influencing bioenergetics. Reduced enzymatic activity of the respiratory chain reported here is also consistent with recent finding of Complex IV deficiency in OPA1-null pancreatic $\beta$-cells. ${ }^{39}$ However, in this model, cells lacking OPA1 maintained normal copy numbers of mtDNA, ${ }^{39}$ whereas we observed mtDNA loss (Figure 4). Our data are in line with the observation that mtDNA content is lower in DOA patients. ${ }^{31}$

Ultrastructure. Several studies have demonstrated that loss of OPA1 (or its yeast ortholog Mgm1) leads to aberrant mitochondrial ultrastructure. ${ }^{17,40-45}$ We observed a number of structural abnormalities consisting of rounded mitochondria with smaller and fewer cristae (not unlike what Amutha et al. $^{40}$ reported for Mgm1 deletion mutants) and a small fraction with condensed matrix or having cristae oriented parallel to the long axis of the organelles. At variance from an earlier study ${ }^{6}$ showing a wide range of abnormal membrane structures in OPA1 siRNA mitochondria, including curved or ring-shaped cristae, unusual cristae shapes were not observed in our model (Figure 2). The variability of reported ultrastructural changes might be due to the different time points of knockdown.

We found that partial cristae depletion is associated with reduction in the number of cristae junction. Crista junction geometry has been proposed to control molecular diffusion inside mitochondria ${ }^{46,47}$ as well as the release of cytochrome $c$ in apoptosis. ${ }^{18,20}$ However, in contrast to observations in pancreatic $\beta$-cells of OPA1 KO mice, ${ }^{39}$ we did not observed dilation of crista junctions. It should be remarked that the crista junction dilation found in the pancreatic $\beta$-cells of OPA1 KO mice could be due to the increased matrix condensation observed in the study. ${ }^{39}$

Impaired mitochondrial $\mathbf{C a}^{2+}$ handling. The clinical manifestation of OPA1 mutations is often highly variable between siblings. ${ }^{48}$ Experimental knockdown of OPA1 performed by different tools and laboratories resulted in highly variable phenotypes (see above). $\mathrm{Ca}^{2+}$ handling is not an exception from this. Here we report diminished agonist-evoked mitochondrial $\mathrm{Ca}^{2+}$ signaling consistent with attenuation of activation of matrix dehydrogenases in OPA1 knockdown cells. In contrast, Fulop et al. ${ }^{22}$ reported increased histamineevoked mitochondrial $\mathrm{Ca}^{2+}$ transients in OPA1 knockdown cells, despite reduced $\Delta \psi_{\mathrm{m}}$, and a hastened kinetics of $\mathrm{Ca}^{2+}$ uptake in the absence of $\Delta \psi_{\mathrm{m}}$. We believe that this discrepancy can be explained by mitochondrial swelling, as they reported a high level of circularity of OPA1 knockdown mitochondria, an indicator of swelling. Mitochondrial $\mathrm{Ca}^{2+}$ fluxes may be controlled by crista junction geometry. ${ }^{46,47}$ Dilation of crista junctions may occur by mechanical forces during overt matrix condensation, ${ }^{39}$ or mitochondrial swelling. When mitochondria swell, crista unfolding might lead to breakdown of the diffusion barrier and increased mitochondrial $\mathrm{Ca}^{2+}$ uptake. In our study, OPA1 knockdown in HeLa cells did not lead to swelling and we observed only small number of condensed mitochondria (Figure 3). The impact of crista and matrix remodeling on mitochondrial $\mathrm{Ca}^{2+}$ transport warrants further investigation. 
a

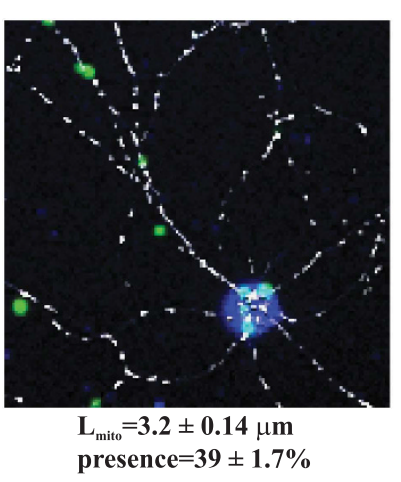

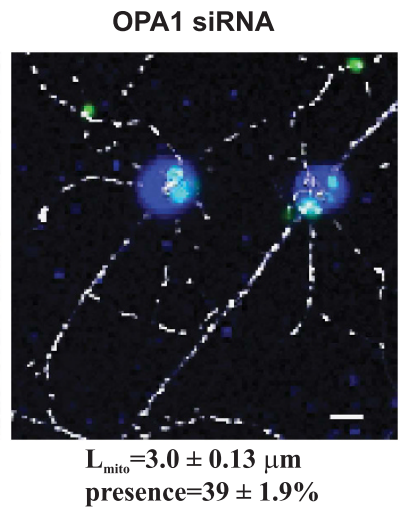

C

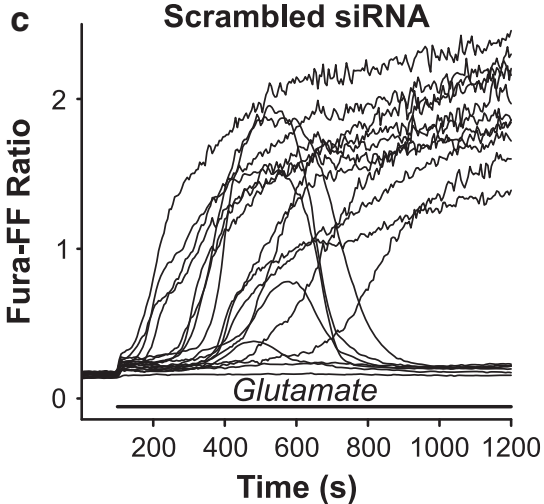

b

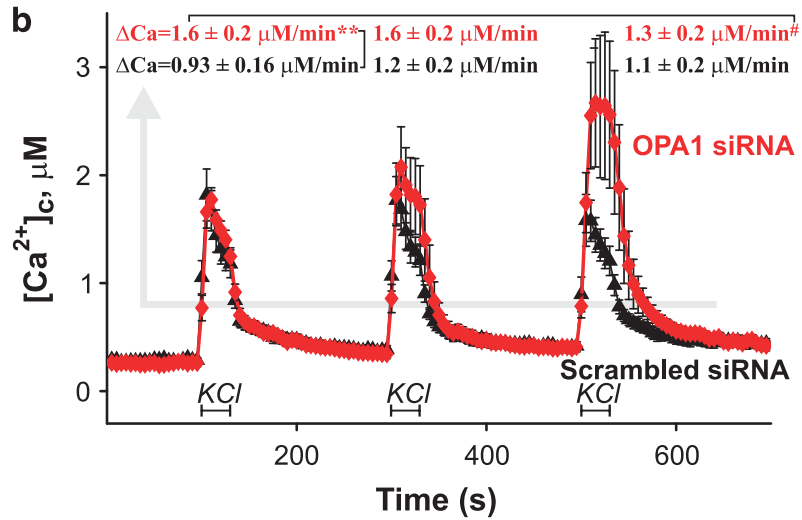

OPA1 SIRNA

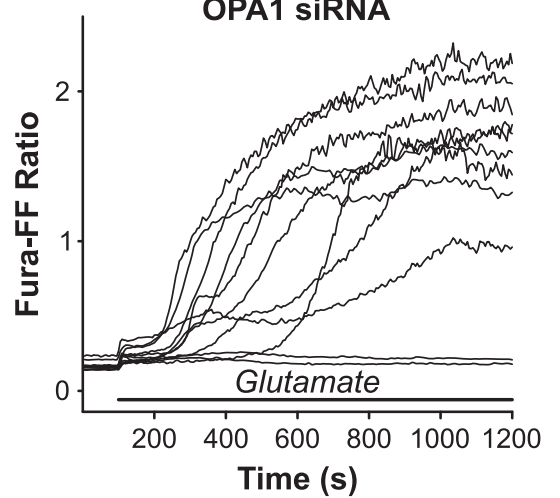

Figure 7 Effect of OPA1 knockdown on intracellular $\left[\mathrm{Ca}^{2+}\right]$ transients in RGCs. RGCs transfected with FAM-conjugated scrambled or OPA1 siRNA were labeled with Fura-FF plus MitoTracker Red and imaged by low-light-level fluorescence microscopy before time-lapse $\mathrm{Ca}^{2+}$ imaging. (a) Mitochondria labeled with MitoTracker Red are visualized in grayscale; the blue color shows the soma marked by Fura-FF fluorescence; and green indicates fluorescence of the siRNA conjugate FAM. Scale bar, $10 \mu \mathrm{m}$. Mitochondrial length $\left(\mathrm{L}_{\text {mito }}\right)$ and the longitudinal fraction of RGC processes occupied by mitochondria (presence) was measured by image segmentation and skeletonization in FAM-positive cells only ( $n=11$ and $n=14$ view fields for scrambled and OPA1 siRNA). See also Supplementary Figure 3. (b) Cytoplasmic [Ca ${ }^{2+}$ transients induced by consecutive depolarization of the plasma membrane with $50 \mathrm{mM} \mathrm{KCl}$ for $30 \mathrm{~s}$, as indicated. Scrambled siRNA and OPA1 siRNA RGCs are represented by black and red traces, respectively. Data points are means \pm S.E.M. of individual FAM-positive cells; for scrambled siRNA, $n=15$ in 4 experiments and for OPA1 siRNA, $n=22$ in 4 experiments. $\mathrm{Ca}^{2+}$ extrusion rates $(\triangle \mathrm{Ca})$ were determined by temporal differentiation of the traces in the recovery phase of the $\mathrm{K}^{+}$-evoked $\left[\mathrm{Ca}^{2+}\right]_{\mathrm{c}}$ transients, where $\left[\mathrm{Ca}{ }^{2+}\right]_{\mathrm{c}}$ was $\sim 0.75 \mu \mathrm{M}$ in average. $\triangle \mathrm{C}$ a was significantly different between OPA1 and scrambled siRNA treatments; $P<0.01$, two-way ANOVA comparing the siRNA treatments as categories. ${ }^{*}$ Significance at $P<0.01$ by Welch-test; ${ }^{*}$ Significance at $P<0.05$ by paired $t$-test. (c) DCD in RGCs. Fura-FF ratio is shown without calibration because of the presence of close to saturation values. Bar below traces indicates timing of perfusion of $100 \mu \mathrm{M}$ glutamate plus $10 \mu \mathrm{M}$ glycine with no $\mathrm{Mg}^{2+}$. Each trace corresponds to an individual FAM-positive cell from three independent cultures of OPA1 $(n=11)$ or scrambled siRNA $(n=18)$-treated RGCs. Of the 18 scrambled siRNA RGCs, 6 showed reversible secondary rise of $\left[\mathrm{Ca}^{2+}\right]_{i}$ compared with 0 of 11 OPA1 siRNA RGCs, $P<0.05$ by one-sided Fisher's exact test

Dayanithi et al. $^{23}$ reported CCCP-triggered increase in intracellular $\mathrm{Ca}^{2+}$ levels after high $\left[\mathrm{K}^{+}\right]$stimulation in OPA1 RNAi RGCs. However, in this study extracellular $\mathrm{Ca}^{2+}$ was not removed from the medium, and therefore it is likely that the observed elevation of $\left[\mathrm{Ca}^{2+}\right]_{\mathrm{c}}$ reflects $\mathrm{Ca}^{2+}$ entry from the extracellular space through voltage-dependent channels upon deenergization by CCCP rather than mitochondrial $\mathrm{Ca}^{2+}$ release.

Our data in permeabilized cells clearly demonstrate that OPA1 knockdown reduces mitochondrial $\mathrm{Ca}^{2+}$ retention capacity (Figure 4E) and are consistent with impaired $\mathrm{Ca}^{2+}$ buffering capacity observed in situ (Figure 5). Interestingly, a similar reduction in $\mathrm{Ca}^{2+}$ retention capacity was observed in dynamin-related protein 1 (Drp1)- and Fis1-expressing cells. ${ }^{49}$ In contrast to the active, electrophoretic $\mathrm{Ca}^{2+}$ uptake addressed in our experiments, OPA1 knockdown resulted in increased rates of passive $\mathrm{Ca}^{2+}$ entry into mitochondria after depolarizing and swelling mitochondria in permeabilized HeLa cells. $^{22}$

Impaired $\mathrm{Ca}^{2+}$ homeostasis and neurodegeneration. Excessive glutamate exposure evokes irreversible, high elevation of $\left[\mathrm{Ca}^{2+}\right]_{\mathrm{c}}$ and the inability of neurons to return to normal $\mathrm{Ca}^{2+}$ homeostasis, ultimately resulting in their demise. ${ }^{25,50}$ We report here that glutamate exposure results in irreversible DCD in OPA1 siRNA RGCs, whereas a significant fraction of control RGCs recovered and exhibited reversible $D C D$, indicating some level of resistance to excitotoxic damage, as was observed earlier. ${ }^{31}$ Interestingly, the NMDA receptor inhibitor memantine is able to protect RGCs in glaucomatous retinas and prevent release of OPA1 from mitochondria. ${ }^{51}$ Using cerebellar granule neurons, Jahani-Asl et al..$^{52}$ showed that NMDA receptor overactivation triggers downstream Calpain activation, loss of OPA1 
oligomers, deformation of crista junctions, and disruption of the respiratory chain complexes. Importantly, calpain activation is secondary to DCD. ${ }^{30}$ Therefore, loss of OPA1 might exert its deleterious effects under excitotoxic conditions by downstream activation of the cell death mediator $\mathrm{Ca}^{2+}$. dependent calpain.

DCD is controlled by two factors: initial mitochondrial $\mathrm{Ca}^{2+}$ load upon glutamate exposure ${ }^{53}$ and bioenergetic capacity of mitochondria. ${ }^{54}$ Based on our data, mitochondrial $\mathrm{Ca}^{2+}$ load is likely to be reduced in OPA1-deficient RGCs, and therefore the aggravation of DCD that was observed is possibly due to the decreased respiratory capacity. Along this line, DOA patients with higher respiratory complex activities have been reported to maintain visual acuity for a longer period of time, ${ }^{48}$ again suggesting that the bioenergetic compromise may be at the root of RGC damage. Because RGC mitochondria do not show any abnormalities in protein expression, the focus should turn to RGC idiosyncrasies in terms of mitochondrial energy metabolism and environmental stress factors. ${ }^{3}$ Our work suggests that inhibitors of excitotoxic injuries should be considered for therapeutic intervention in DOA.

\section{Materials and Methods}

Unless indicated otherwise, chemicals were of analytical or molecular biology grade and purchased from Sigma-Aldrich (St. Louis, MO, USA) or Thermo-Fisher Scientific (Waltham, MA, USA).

Cell culture. HeLa cells were purchased from American Tissue Culture Company (ATCC; Manassas, VA, USA) and grown in Dulbecco's modified Eagle's medium (DMEM; HyClone-Thermo-Fisher, Logan, UT, USA) containing $4.5 \mathrm{~g} / \mathrm{l}$ glucose, $2 \mathrm{mM}$ L-glutamine, $10 \%$ fetal bovine serum (FBS) (Tissue Culture Biologicals, Los Alamitos, CA, USA), containing 100 units $/ \mathrm{ml}$ penicillin and $1000 \mu \mathrm{g} / \mathrm{ml}$ streptomycin (Invitrogen, Carlsbad, CA, USA). RGCs were isolated from postnatal rats by immunopanning ${ }^{36}$ and used at 7 days in vitro.

RNA interference. Scrambled I duplex (control) and OPA1 siRNA, the latter corresponding to nucleotides 1810-1833 of the OPA1 open reading frame (GenBank accession number AB011139) were from Dharmacon (Lafayette, CO, USA). SiRNA (100-200nM) was transfected into HeLa or RGCs with Oligofectamine (Invitrogen). To verify siRNA transfer in RGCs, siRNA was labeled with FAM (Ambion, Austin, TX, USA). Experiments were performed on day 3 after transfection.

Subcellular fractionation and immunoblotting. Subcellular fractionation and immunoblotting were done as described previously. ${ }^{55}$ The primary antibody for cytochrome $c$ was mouse monoclonal anti-cytochrome $c(1: 1000$; clone 7H8.2.84; BD Biosciences Pharmingen, Franklin Lakes, NJ, USA). The OPA1 antibody $(1: 1000)$ was a gift from Dr. Kubo. Blots were probed with secondary HRP-conjugated anti-mouse antibody (1:2000; Amersham Biosciences, Piscataway, $\mathrm{NJ}, \mathrm{USA}$ ) for $2 \mathrm{~h}$ and immunocomplexes were visualized using a chemiluminescence detection kit (ECL) (Amersham Biosciences).

Fluorescence microscopy. HeLa cells were grown on $35 \mathrm{~mm}$ MatTek glass bottom dishes and mitochondria were labeled with $100 \mathrm{nM}$ MitoTracker Red CMXRos (Molecular Probes, Eugene, OR, USA) for $20 \mathrm{~min}$ in culture medium. Cells were fixed with $0.5 \%$ glutaraldehyde (Ted Pella, Redding, CA, USA) in icecold PBS (HyClone-Thermo-Fisher) for $30 \mathrm{~min}$ and autofluorescence was quenched by $1 \%$ sodium borohydrite (Sigma-Aldrich) for $30 \mathrm{~min}$ at room temperature. Nuclei were stained with Hoechst $33342(0.1 \mu \mathrm{g} / \mathrm{ml}$; Molecular Probes). The 3D images were acquired using a Zeiss Axiovert 100M fluorescence microscope (Oberkochen, Germany) equipped with a Sensicam CCD camera controlled by Slidebook software (Intelligent Imaging Innovation, Denver, CO, USA). The $z$-series were deconvolved using the Slidebook constrained iterative algorithm and volumes were surfacerendered using Volocity 2 (Improvision, Coventry, UK).
Electron microscopy. HeLa cells were fixed as described. ${ }^{42}$ Roughly $80-\mathrm{nm}$ thick sections were cut with a Reichert (Cambridge, England, UK) ultramicrotome and poststained $10 \mathrm{~min}$ in uranyl acetate and $2 \mathrm{~min}$ in Sato lead. Sections were examined using a JEOL (Peabody, MA, USA) 1200FX electron microscope operated at $80 \mathrm{kV}$. Images were recorded on film at 6000 magnification. The negatives were digitized at 1200 d.p.i. using a Nikon (Melville, NY, USA) CoolScan system, giving an image size of $2689 \times 4006$ pixel array and a pixel resolution of $4.2 \mathrm{~nm}$.

EM tomography. Sections from in situ embedded monolayers of scrambled or OPA1 siRNA-transfected HeLa cells were cut at a thickness of 400-500 nm. EM tomography was performed as described. ${ }^{56}$ Measurements of structural features were made within segmented volumes by the programs Synuarea and Synuvolume (National Center for Microscopy and Imaging Research, San Diego, CA, USA). Numbers of mitochondria were counted in the volume and normalized by dividing by the cytoplasmic volume reconstructed.

Q-PCR. To quantify mtDNA, real-time PCR was performed as described ${ }^{57}$ using a Mx3000P real time PCR system (Stratagene, La Jolla, CA, USA) and SYBR Green PCR Master Mix (Applied Biosystems, Foster City, CA, USA). Total cellular DNA was purified with a PUREGENE Cell \& Tissue kit (Gentra Systems, Minneapolis, MN, USA) 3 days after siRNA transfection. Serially diluted total cellular DNA from untransfected cells was used as a template for two standard DNA curves, one for amplification with nDNA primers and the second one with mtDNA primers. The relative quantity of amplified DNA was determined from respective standard curves for each sample, starting with $10 \mathrm{ng}$ for nDNA and $0.1 \mathrm{ng}$ for $\mathrm{mtDNA}$ and the $\mathrm{mtDNA} / \mathrm{nDNA}$ ratio was calculated.

ATP measurements and cell viability. HeLa cells were plated on black 96-well plates (Costar, Corning, Corning, NY, USA). ATP levels were determined using a CellTiter-Glo luminescence assay kit (Promega, Madison, WI, USA). Luminescence was measured in a PolarStar plate reader (BMG, Berlin, Germany). Each data set was collected from replicate wells $(n=6)$.

For cell viability measurements, cells were loaded with $2 \mu \mathrm{M}$ Calcein-AM (Molecular Probes) in PBS. Generation of fluorescent Calcein was followed for $20 \mathrm{~min}$ at $490 \mathrm{~nm}$ excitation and $540 \mathrm{~nm}$ emission using a PolarStar plate reader. Cell viability of scrambled or OPA1 siRNA-transfected cells was expressed as the percentage of the rate of Calcein-AM hydrolysis measured from untransfected control cells (defined as 100\%). Each data set was collected from replicate wells $(n=6-8)$. Caspase activity was measured using the fluorogenic substrate z-DEVDAMC (Molecular Probes). Apoptotic cell death was measured by Annexin-V-FITC staining as described previously. ${ }^{42}$

Cytochrome $c$ immunocytochemistry and confocal microscopy. HeLa cells were grown on MatTek dishes and fixed with 3.7\% formaldehyde in $\mathrm{KCl}$-based PIPES-KOH, pH 7.2, buffer containing $5 \%$ sucrose, for 15 min at $37^{\circ} \mathrm{C}$ and permeabilized with $1 \%$ Triton in PBS for $20 \mathrm{~min}$ at $37^{\circ} \mathrm{C}$. Non-specific binding was blocked in $2 \% \mathrm{BSA}, 0.05 \%$ Tween-20, and $0.1 \% \mathrm{NaN}_{3}$ for $40 \mathrm{~min}$ at $37^{\circ} \mathrm{C}$. Samples were incubated with anti-cytochrome $c$ antibodies in blocking solution $(1: 200$, subclone $6 \mathrm{H} 2 \mathrm{~B} 4, \mathrm{BD}$ PharMingen, San Diego, CA, USA) overnight at $4^{\circ} \mathrm{C}$. Samples were incubated with secondary Alexa488-conjugated antibodies $(1: 200$, Molecular Probes) for $2 \mathrm{~h}$ at room temperature. Confocal imaging was carried out using an Olympus (Tokyo, Japan) Fluoview-1000 laser scanning confocal microscope. Image stacks of $800 \times 800$ pixels, 20 planes $\left(0.09 \times 0.09 \times 0.5 \mathrm{~mm}^{3}\right.$ voxel size) were recorded and projected over maximum intensity. For excitation of Hoechst 33342, Alexa-488, and MitoTracker Red, the 405, 488, and 543nm laser lines of a diode, an Ar-ion, and a He-Ne laser, respectively, were used. Emission was detected through a DM405/488/543 dichromic mirror and the spectral detector of the microscope at $420-480,500-530$, and $>560 \mathrm{~nm}$, respectively.

Respiration measurements. Oxygen consumption was measured using a Clark-type electrode (Oxygraph, Hansatech Instruments, King's Lynn, UK). HeLa cells were trypsinized, centrifuged at $500 \times g$, and resuspended in the culture medium. For measurements in intact cells, $8 \times 10^{6}$ cells were pelleted at $200 \times \mathrm{g}$, $2 \mathrm{~min}$ and resuspended in $1 \mathrm{ml} \mathrm{DMEM}$. After recording basal respiration for 2 to $3 \mathrm{~min}$, oligomycin $(1.25 \mu \mathrm{g} / \mathrm{ml})$ was added followed by sequential additions of FCCP $(100 \mathrm{nM})$. Respiration rates were normalized for equal numbers of live cells, evaluated by Trypan Blue exclusion.

For measurements in permeabilized cells, $8 \times 10^{6}$ cells were resuspended in $1 \mathrm{ml}$ buffer containing $250 \mathrm{mM}$ sucrose, $10 \mathrm{mM}$ HEPES/KOH, pH 7.4, $2 \mathrm{mM}$ 
$\mathrm{KH}_{2} \mathrm{PO}_{4}$, centrifuged at $200 \times \mathrm{g}, 2 \mathrm{~min}$, and resuspended in $1 \mathrm{ml}$ of respiration buffer containing $125 \mathrm{mM} \mathrm{KCl}, 20 \mathrm{mM} \mathrm{HEPES} / \mathrm{KOH}, \mathrm{pH} 7.4,2 \mathrm{mM} \mathrm{KH}_{2} \mathrm{PO}_{4}$, and $1 \mathrm{mM} \mathrm{MgCl}$. Then, $5 \mathrm{mM}$ glutamate and $5 \mathrm{mM}$ malate were added as respiratory substrates. The plasma membrane was permeabilized by addition of titrated amounts of digitonin $(0.012 \%)$. ADP $(200 \mu \mathrm{M})$, oligomycin $(1.25 \mu \mathrm{g} / \mathrm{ml})$, and FCCP $(200 \mathrm{nM})$ were added, as noted.

\begin{abstract}
Measurements of mitochondrial $\mathrm{Ca}^{2+}$ retention capacity, $\Delta \psi_{\mathrm{m}}$, and mitochondrial swelling. A custom-made chamber was used to simultaneously measure $\left[\mathrm{Ca}^{2+}\right], \Delta \psi_{\mathrm{m}}$, and optical density at $660 \mathrm{~nm}$ as described previously. ${ }^{58}$ To measure the $\mathrm{Ca}^{2+}$ retention capacity, $8 \times 10^{6}$ siRNA-transfected cells were permeabilized with digitonin $(0.012 \%)$ in $1 \mathrm{ml}$ of sucrose-based buffer and pelleted at $200 \times g$. Cells were resuspended in the respiration buffer plus $2 \mu \mathrm{M}$ tetraphenylphosphonium (TPP ${ }^{+}$) and without $\mathrm{MgCl}_{2}$ and pulsed with successive $\mathrm{Ca}^{2+}(50 \mu \mathrm{M})$ additions. $\mathrm{Ca}^{2+}$ retention capacity was defined as the amount of $\mathrm{Ca}^{2+}$ required to induce $\Delta \psi_{\mathrm{m}}$ loss and $\mathrm{Ca}^{2+}$ release.
\end{abstract}

Measurements of Complex I-III-IV enzyme activity. An assay of mitochondrial enzyme activity using a pore-forming peptide, alamethicin, has been described. ${ }^{59}$ Briefly, $8 \times 10^{6}$ cells were permeabilized with $0.012 \%$ digitonin and mitochondria were permeabilized with $30 \mu \mathrm{g} / \mathrm{ml}$ alamethicin in respiration buffer (see above) containing $2 \mu \mathrm{M}$ cytochrome $c$. Oxygen consumption induced by $2 \mathrm{mM} \mathrm{NADH}$ was measured for 2 to $3 \mathrm{~min}$ followed by rotenone $(2 \mu \mathrm{M})$ addition. The rate of rotenone-insensitive respiration was subtracted from the total rate of NADH-dependent respiration.

Fluorescence time-lapse imaging for $\mathrm{Ca}^{2+}$ and NADH. For simultaneous measurements of $\left[\mathrm{Ca}^{2+}\right]_{m}$ and $\left[\mathrm{Ca}^{2+}\right]_{c}$, cells were loaded with $2 \mu \mathrm{M}$ Rhod-2-AM (Molecular Probes) in the presence of $15 \mathrm{mM}$ malate for $15 \mathrm{~min}$ at $37^{\circ} \mathrm{C}$. To measure $\left[\mathrm{Ca}^{2+}\right]_{\mathrm{c}}$ in RGCs, neurons were loaded with $1 \mu \mathrm{M}$ Fura-FFAM (Molecular Probes) for $10 \mathrm{~min}$ at $37^{\circ} \mathrm{C}$. To visualize mitochondria, $2 \mathrm{nM}$ MitoTracker Red was included. High-speed, live-cell imaging was performed in perfusion buffer containing $140 \mathrm{mM} \mathrm{NaCl}, 3.9 \mathrm{mM} \mathrm{KCl}, 1.8 \mathrm{mM} \mathrm{CaCl}_{2}, 0.8 \mathrm{mM}$ $\mathrm{MgCl}_{2}, 1.2 \mathrm{mM} \mathrm{Na}_{2} \mathrm{SO}_{4}, 0.4 \mathrm{mM} \mathrm{Na} \mathrm{HPO}_{4}, 5.6 \mathrm{mM}$ D-glucose, and $20 \mathrm{mM}$ HEPES, pH 7.4. Cells on coverslips were placed in a perfusion chamber on the stage of an Olympus IX81 inverted microscope. Fluorescence was excited by a DG-4 (Sutter Instruments, Novato, CA, USA) Xenon-arc illumination unit through $340 / 10 \mathrm{~nm}$ and $380 / 10 \mathrm{~nm}$ bandpass filters for Fura-FF, a $492 / 18 \mathrm{~nm}$ filter for FAM, a $525 / 30 \mathrm{~nm}$ filter for Rhod2-AM, and a $572 / 25 \mathrm{~nm}$ filter for MitoTracker Red. Fluorescence was detected by an ultra-sensitive cooled CCD camera (Photometrics Cascade 512B; Roper Scientific, Vista, CA, USA) through emission filters: $510 / 40 \mathrm{~nm}$ for Fura-FF, 535/20 nm for FAM, 600/45 nm for Rhod-2-AM, and $630 / 60 \mathrm{~nm}$ for MitoTracker Red. Data acquisition was controlled by Metafluor 6.2 (Molecular Devices, Silicon Valley, CA, USA).

For selective assessment of $\left[\mathrm{Ca}^{2+}\right]_{\mathrm{m}}$, high-resolution images were taken ( $512 \times 51216$-bit $0.26 \mu \mathrm{m} / \mathrm{pixel}$; at $5 \mathrm{~s}$ intervals) and fluorescence originating from mitochondria was separated by high-pass filtering of fluorescent images, whereas $\left[\mathrm{Ca}^{2+}\right]_{\mathrm{c}}$ was determined over the nucleus ${ }^{35}$ using Metafluor Analyst (Molecular Devices).

For RGCs, MitoTracker Red and FAM fluorescence was measured once at the start of the experiment $(512 \times 51216$-bit $0.8 \mu \mathrm{m} / \mathrm{pixel})$. Length and presence of mitochondria in processes of RGCs were determined by high-pass filtering and segmentation of images using locally adaptive techniques in Image Analyst MKII. Finally, the skeletal length of mitochondria and processes were calculated for FAMpositive cells. Mitochondrial length is given as mean skeletal length. Mitochondrial presence is defined as total mitochondrial length per total neurite length (see Supplementary Figure 3B). During time-lapse experiments, Fura-FF signals were recorded at $2 \times 2$ binning $(256 \times 256$; 16 -bit; $1.6 \mu \mathrm{m} /$ pixel; 5 s/ratio frame). Fura-FF $\left(K_{d}=2.9 \mu \mathrm{M}\right)$ ratios were calibrated to $\left[\mathrm{Ca}^{2+}\right]$ by exposing each sample to zero and high $(10 \mathrm{mM})\left[\mathrm{Ca}^{2+}\right]$ at the end of the experiment with a procedure previously described. ${ }^{30}$ The $\mathrm{Ca}^{2+}$ calibration and analysis of $\mathrm{Ca}^{2+}$ extrusion rates were performed in Mathematica 5.2 (Wolfram Research, Oxfordshire, England, UK).

$\mathrm{NADH}$ autofluorescence in HeLa cells was measured using $340 / 10 \mathrm{~nm}$ excitation and $465 / 30 \mathrm{~nm}$ emission filters. Images were taken at $256 \times 256$ pixels; 16 -bit; $0.8 \mu \mathrm{m} / \mathrm{pixel}$, at $10 \mathrm{~s}$ intervals. Decay slope and half-life of fluorescence transients in histamine-stimulated cells were determined by standard functions in Mathematica 5.2. The percentage of $N A D(H)$ reduction was expressed from the $N A D(P) H$ autofluorescence intensity before application of FCCP scaled between the intensities measured in the presence of FCCP $(0 \%)$ and rotenone $(100 \%)$.

\section{Conflict of Interest}

The authors declare no conflict of interest.

Acknowledgements. We thank Dr. E Monosov for help in fluorescence imaging, Dr. B Barres and colleagues for teaching us to prepare RGC cultures, Dr. Y Kubo for OPA1 antibodies, Dr. A Andreyev for critical reading of the manuscript, and WD Lee for technical assistance. This work was supported by NIH Grants R01 NS047456, R01 NS047456, and R01 EY016164 (to EB-W), NIH Grant R01 EY018658 (to W-KJ), and NIH Grants P41RR004050 and R01 NS14718 (to MHE).

1. Alexander C, Votruba M, Pesch UE, Thiselton DL, Mayer S, Moore A et al. OPA1, encoding a dynamin-related GTPase, is mutated in autosomal dominant optic atrophy linked to chromosome 3q28. Nat Genet 2000; 26: 211-215.

2. Delettre C, Lenaers G, Griffoin JM, Gigarel N, Lorenzo C, Belenguer P et al. Nuclear gene OPA1, encoding a mitochondrial dynamin-related protein, is mutated in dominant optic atrophy. Nat Genet 2000; 26: 207-210.

3. Lenaers G, Reynier P, Elachouri G, Soukkarieh C, Olichon A, Belenguer P et al. OPA1 functions in mitochondria and dysfunctions in optic nerve. Int J Biochem Cell Biol 2009; 41: 1866-1874.

4. Ju WK, Misaka T, Kushnareva Y, Nakagomi S, Agarwal N, Kubo Y et al. OPA1 expression in the normal rat retina and optic nerve. J Comp Neurol 2005; 488: 1-10.

5. Pesch UE, Fries JE, Bette S, Kalbacher H, Wissinger B, Alexander C et al. OPA1, the disease gene for autosomal dominant optic atrophy, is specifically expressed in ganglion cells and intrinsic neurons of the retina. Invest Ophthalmol Vis Sci 2004; 45: 4217-4225.

6. Aijaz S, Erskine L, Jeffery G, Bhattacharya SS, Votruba M. Developmental expression profile of the optic atrophy gene product: OPA1 is not localized exclusively in the mammalian retinal ganglion cell layer. Invest Ophthalmol Vis Sci 2004; 45: 1667-1673.

7. Williams PA, Morgan JE, Votruba M. Opa1 deficiency in a mouse model of dominant optic atrophy leads to retinal ganglion cell dendropathy. Brain 2010; 133: 2942-2951.

8. Yu-Wai-Man P, Griffiths PG, Chinnery PF. Mitochondrial optic neuropathies - disease mechanisms and therapeutic strategies. Prog Retin Eye Res 2011; 30: 81-114.

9. Olichon A, Baricault L, Gas N, Guillou E, Valette A, Belenguer P et al. Loss of OPA1 perturbates the mitochondrial inner membrane structure and integrity, leading to cytochrome c release and apoptosis. J Biol Chem 2003; 278: 7743-7746.

10. Griparic L, van der Wel NN, Orozco IJ, Peters PJ, van der Bliek AM. Loss of the intermembrane space protein Mgm1/OPA1 induces swelling and localized constrictions along the lengths of mitochondria. J Biol Chem 2004; 279: 18792-18798.

11. Arnoult $D$, Grodet A, Lee YJ, Estaquier J, Blackstone C. Release of OPA1 during apoptosis participates in the rapid and complete release of cytochrome $c$ and subsequent mitochondrial fragmentation. J Biol Chem 2005; 280: 35742-35750.

12. Ban T, Heymann JA, Song Z, Hinshaw JE, Chan DC. OPA1 disease alleles causing dominant optic atrophy have defects in cardiolipin-stimulated GTP hydrolysis and membrane tubulation. Hum Mol Genet 2010; 19: 2113-2122.

13. Frey TG, Mannella CA. The internal structure of mitochondria. Trends Biochem Sci 2000; 25: 319-324.

14. Perkins G, Bossy-Wetzel E, Ellisman MH. New insights into mitochondrial structure during cell death. Exp Neurol 2009; 218: 183-192.

15. Zick M, Rabl R, Reichert AS. Cristae formation-linking ultrastructure and function of mitochondria. Biochim Biophys Acta 2009; 1793: 5-19.

16. Darshi M, Mendiola VL, Mackey MR, Murphy AN, Koller A, Perkins GA et al. ChChd3, an inner mitochondrial membrane protein, is essential for maintaining crista integrity and mitochondrial function. J Biol Chem 2011; 286: 2918-2932.

17. Frezza C, Cipolat S, Martins de Brito O, Micaroni M, Beznoussenko GV, Rudka T et al. OPA1 controls apoptotic cristae remodeling independently from mitochondrial fusion. Cell 2006; 126: 177-189.

18. Yamaguchi R, Lartigue L, Perkins G, Scott RT, Dixit A, Kushnareva Y et al. Opa1-mediated cristae opening is Bax/Bak and $\mathrm{BH} 3$ dependent, required for apoptosis, and independent of Bak oligomerization. Mol Cell 2008; 31: 557-569.

19. Sun MG, Williams J, Munoz-Pinedo C, Perkins GA, Brown JM, Ellisman MH et al. Correlated three-dimensional light and electron microscopy reveals extensive transformation of the mitochondrial inner membrane during apoptosis. Nat Cell Biol 2007; 9: 1057-1065.

20. Scorrano L, Ashiya M, Buttle K, Weiler S, Oakes SA, Mannella CA et al. A distinct pathway remodels mitochondrial cristae and mobilizes cytochrome $c$ during apoptosis. Dev Cell 2002; 2: 55-67.

21. Yamaguchi R, Perkins G. Dynamics of mitochondrial structure during apoptosis and the enigma of Opa1. Biochim Biophys Acta 2009; 1787: 963-972.

22. Fulop L, Szanda G, Enyedi B, Varnai P, Spat A. The effect of OPA1 on mitochondrial $\mathrm{Ca}(2)$ signaling. PloS One 2011; 6: e25199.

23. Dayanithi G, Chen-Kuo-Chang M, Viero C, Hamel C, Muller A, Lenaers G. Characterization of $\mathrm{Ca}^{2+}$ signalling in postnatal mouse retinal ganglion cells: involvement of OPA1 in $\mathrm{Ca}^{2+}$ clearance. Ophthalmic Genet 2010; 31: 53-65.

24. Denton RM. Regulation of mitochondrial dehydrogenases by calcium ions. Biochim Biophys Acta 2009; 1787: 1309-1316. 
25. Mattson MP. Calcium and neurodegeneration. Aging Cell. 2007; 6, 337-350.

26. Manev H, Favaron M, Guidotti A, Costa E. Delayed increase of $\mathrm{Ca}^{2+}$ influx elicited by glutamate: role in neuronal death. Mol Pharmacol 1989; 36: 106-112.

27. Randall RD, Thayer SA. Glutamate-induced calcium transient triggers delayed calcium overload and neurotoxicity in rat hippocampal neurons. J Neurosci 1992; 12: 1882-1895.

28. Budd SL, Nicholls DG. Mitochondria, calcium regulation, and acute glutamate excitotoxicity in cultured cerebellar granule cells. J Neurochem 1996; 676: 2282-2291.

29. Abramov AY, Duchen MR. Impaired mitochondrial bioenergetics determines glutamateinduced delayed calcium deregulation in neurons. Biochim Biophys Acta 2010; 1800 297-304.

30. Gerencser AA, Mark KA, Hubbard AE, Divakaruni AS, Mehrabian Z, Nicholls DG et al. Real-time visualization of cytoplasmic calpain activation and calcium deregulation in acute glutamate excitotoxicity. J Neurochem 2009; 110: 990-1004.

31. Ullian EM, Barkis WB, Chen S, Diamond JS, Barres BA. Invulnerability of retinal ganglion cells to NMDA excitotoxicity. Mol Cell Neurosci 2004; 26: 544-557.

32. Lee YJ, Jeong SY, Karbowski M, Smith CL, Youle RJ. Roles of the mammalian mitochondrial fission and fusion mediators Fis1, Drp1, and Opa1 in apoptosis. Mol Biol Cell 2004; 15: 5001-5011.

33. Chen $\mathrm{H}$, Chomyn $\mathrm{A}$, Chan DC. Disruption of fusion results in mitochondrial heterogeneity and dysfunction. J Biol Chem 2005; 280: 26185-26192.

34. Perkins GA, Renken CW, Frey TG, Ellisman MH. Membrane architecture of mitochondria in neurons of the central nervous system. J Neurosci Res 2001; 66: 857-865.

35. Gerencser AA, Adam-Vizi V. Selective, high-resolution fluorescence imaging of mitochondrial $\mathrm{Ca}^{2+}$ concentration. Cell Calcium 2001; 30: 311-321.

36. Barres BA, Silverstein BE, Corey DP, Chun LL. Immunological, morphological, and electrophysiological variation among retinal ganglion cells purified by panning. Neuron 1988; 1: 791-803.

37. Kamei S, Chen-Kuo-Chang M, Cazevieille C, Lenaers G, Olichon A, Belenguer $P$ et al. Expression of the Opa1 mitochondrial protein in retinal ganglion cells: its downregulation causes aggregation of the mitochondrial network. Invest Ophthalmol Vis Sci 2005; 46: 4288-4294.

38. Lodi R, Tonon C, Valentino ML, lotti S, Clementi V, Malucelli $E$ et al. Deficit of in vivo mitochondrial ATP production in OPA1-related dominant optic atrophy. Ann Neurol 2004 56: 719-723.

39. Zhang Z, Wakabayashi N, Wakabayashi J, Tamura Y, Song WJ, Sereda S et al. The dynamin-related GTPase Opa1 is required for glucose-stimulated ATP production in pancreatic beta cells. Mol Biol Cell 2011; 22: 2235-2245.

40. Amutha B, Gordon DM, Gu Y, Pain D. A novel role of Mgm1p, a dynamin-related GTPase, in ATP synthase assembly and cristae formation/maintenance. Biochem J. 2004; 381: $19-23$.

41. Meeusen S, DeVay R, Block J, Cassidy-Stone A, Wayson S, McCaffery JM et al Mitochondrial inner-membrane fusion and crista maintenance requires the dynamin-related GTPase Mgm1. Cell 2006; 127: 383-395.

42. Misaka T, Murate M, Fujimoto K, Kubo Y. The dynamin-related mouse mitochondria GTPase OPA1 alters the structure of the mitochondrial inner membrane when exogenously introduced into COS-7 cells. Neurosci Res 2006; 55: 123-133.
43. Sesaki H, Southard SM, Yaffe MP, Jensen RE. Mgm1p, a dynamin-related GTPase, is essential for fusion of the mitochondrial outer membrane. Mol Biol Cell 2003; 14: 2342-2356.

44. Song Z, Ghochani M, McCaffery JM, Frey TG, Chan DC. Mitofusins and OPA1 mediate sequential steps in mitochondrial membrane fusion. Mol Biol Cell 2009; 20: 3525-3532.

45. Vogel F, Bornhovd C, Neupert W, Reichert AS. Dynamic subcompartmentalization of the mitochondrial inner membrane. J Cell Biol 2006; 175: 237-427.

46. Mannella CA. The relevance of mitochondrial membrane topology to mitochondrial function. Biochim Biophys Acta 2006; 1762: 140-147.

47. Sukhorukov VM, Bereiter-Hahn J. Anomalous diffusion induced by cristae geometry in the inner mitochondrial membrane. PloS One 2009; 4: e4604.

48. Van Bergen NJ, Crowston JG, Kearns LS, Staffieri SE, Hewitt AW, Cohn AC et al. Mitochondrial oxidative phosphorylation compensation may preserve vision in patients with OPA1-linked autosomal dominant optic atrophy. PloS One 2011; 6: e21347.

49. Kong D, Xu L, Yu Y, Zhu W, Andrews DW, Yoon Y et al. Regulation of $\mathrm{Ca} 2+$-induced permeability transition by Bcl-2 is antagonized by Drpl and hFis1. Mol Cell Biochem 2005; 272: $187-199$

50. Nicholls DG. Mitochondrial calcium function and dysfunction in the central nervous system. Biochim Biophys Acta 2009; 1787: 1416-1424.

51. Ju WK, Kim KY, Angert M, Duong-Polk KX, Lindsey JD, Ellisman MH et al. Memantine blocks mitochondrial OPA1 and cytochrome $c$ release and subsequent apoptotic cell death in glaucomatous retina. Invest Ophthalmol Vis Sci 2009; 50: 707-716.

52. Jahani-Asl A, Pilon-Larose K, Xu W, MacLaurin JG, Park DS, McBride HM et al. The mitochondrial inner membrane GTPase, optic atrophy 1 (Opa1), restores mitochondrial morphology and promotes neuronal survival following excitotoxicity. J Biol Chem 2011; 286: $4772-4782$.

53. Castilho RF, Hansson O, Ward MW, Budd SL, Nicholls DG. Mitochondrial control of acute glutamate excitotoxicity in cultured cerebellar granule cells. J Neurosci 1998; 18: 10277-10286

54. Yadava N, Nicholls DG. Spare respiratory capacity rather than oxidative stress regulates glutamate excitotoxicity after partial respiratory inhibition of mitochondrial complex I with rotenone. J Neurosci 2007; 27: 7310-7317.

55. Bossy-Wetzel E, Newmeyer DD, Green DR. Mitochondrial cytochrome c release in apoptosis occurs upstream of DEVD-specific caspase activation and independently of mitochondrial transmembrane depolarization. EMBO J 1998; 17: 37-49.

56. Lawrence A, Bouwer JC, Perkins G, Ellisman MH. Transform based backprojection for volume reconstruction of large format electron microscope tilt series. J Struct Biol 2006; 154: $144-167$

57. Wong A, Cortopassi G. Reproducible quantitative PCR of mitochondrial and nuclear DNA copy number using the LightCycler. Methods Mol Biol 2002; 197: 129-137.

58. Kushnareva YE, Wiley SE, Ward MW, Andreyev AY, Murphy AN. Excitotoxic injury to mitochondria isolated from cultured neurons. J Biol Chem 2005; 280: 28894-28902

59. Gostimskaya IS, Grivennikova VG, Zharova TV, Bakeeva LE, Vinogradov AD. In situ assay of the intramitochondrial enzymes: use of alamethicin for permeabilization of mitochondria. Anal Biochem 2003; 313: 46-52.

Supplementary Information accompanies the paper on Cell Death and Differentiation website (http://www.nature.com/cdd) 